\title{
Plant Abiotic Stress: Insights from the Genomics Era
}

\author{
Erik R. Rowley and Todd C. Mockler \\ Oregon State University \\ United States
}

\section{Introduction}

Agricultural crop plants make up a large proportion of the world's economy and in many countries constitute the main sustenance for humans. Therefore maximizing crop yield is of extreme importance and interest. There are many factors that can limit the yield of a crop; however the main causes of crop failure are abiotic stresses such as salinity, drought, extremes in temperature, intense light, and oxidative stress caused by reactive oxygen species. Plants have evolved mechanisms and pathways allowing them to cope with the environment by modifying their physiological and cellular states. For example, plants living in colder regions undergo a phenomenon known as cold acclimation, resulting in cell membrane composition and protein concentration changes to reduce intracellular ice crystal formation and dehydration due to freezing (Thomashow, 1998).

Abiotic stresses alter gene networks and signaling cascades in an effort to restore cellular homeostasis. It has been demonstrated (Reddy, 2007, Palusa et al., 2007) that abiotic stress conditions alter the alternative splicing of a number of genes. Alternative pre-mRNA splicing in higher eukaryotes is a highly regulated mechanism, often allowing for many proteins (isoforms) to be derived from a single gene, thereby increasing overall proteome diversity. These alternative transcripts often result in functionally and structurally distinct proteins (Biamonti, 2009) with their own functions in development, cellular localization, and responses to the environment (Tanabe et al., 2006).

Recently genome and transcriptome-wide surveys (Rensink et al., 2005, Kreps et al., 2002, Egawa et al., 2006, Filichkin et al., 2010) have offered glimpses into transcript abundance profiles under abiotic stresses, demonstrating dramatic shifts in alternative splicing patterns, as well as upregulation of key transcription factors controlling stress-induced signaling cascades. This research offers the potential for discovery of candidate genes that, through genetic engineering, may confer increased tolerance to abiotic stresses, several examples of which will be discussed in this chapter.

Recent research has demonstrated the possibility of pre-disposing plants to stress tolerance by overexpressing a gene known to be upregulated in response to a certain stress (for example: Haake et al., 2002, Forment et al., 2002, Kim et al., 2010) often acting upstream or in conjunction with a longer signaling cascade, such as the mitogen-activated protein (MAP) kinase cascade (Xiong et al. 2003), salt overly sensitive (SOS) pathway (Liu and Zhu, 1998; Ishitani et al., 2000, Qiu et al., 2004), or C-repeat-binding factor/dehydration-responsive element (CBF/DREB) pathway (Thomashow, 2010). 
A high degree of crosstalk exists between these pathways, as often the plant's physiological and cellular responses to different abiotic stresses are similar (Figure 1). In drought and cold stress for example, two types of molecular responses occur simultaneously: those protecting cells from acute dehydration and those protein factors involved in further regulation of gene expression and signal transduction functioning in overall stress response (Shinozaki et al., 2000 and 2007). Other examples include crosstalk between cold and osmotic signaling pathways, as well as cold and abscisic acid (Ishitani et al., 1997). Abscisic acid regulates stomatal aperture changes and is a crucial signaling molecule in stress plant responses along with changes in metabolite concentrations.

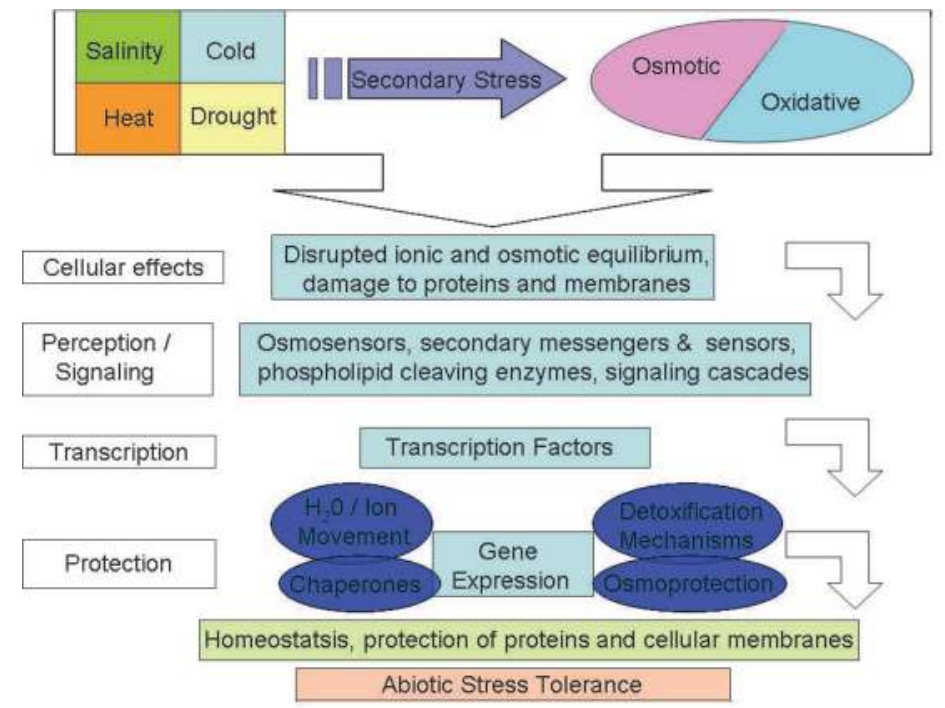

Fig. 1. Depiction of the overlapping and complex cellular responses resulting from abiotic stressors. These responses are a recurring theme throughout the chapter, as responses to many stress overlap, sharing regulons and transcriptional "hubs". Primary stresses (cold, drought, heat, and cold) result in secondary stresses, such as altered osmotic or ionic potential. The cell senses initial stress signals, such as osmotic and ionic effects, temperature, membrane fluidity changes, and triggers downstream signaling cascades, and amplifications of the signal. The final layer is the transcription factors, which initiate stressresponsive mechanisms in order to protect the cell, and restore homeostasis (Figure adapted from review by Wang et al., 2003).

Understanding the genes and gene networks that underlie abiotic stress resistance is integral not only in improving the world's long term food production and security, but also in piecing together the web of abiotic stress induced global gene regulation including posttranscriptional regulation such as alternative splicing and regulation by miRNAs. Recent insights into genes conferring abiotic stress tolerance, particularly salt tolerance, have come from the study of plants naturally adapted for growth in extreme conditions such as the halophytes, which thrive in areas of elevated salt levels. Differential gene expression in seedlings of the salt marsh halophyte Kosteletzkya virginica was recently analyzed (Guo et al., 2009), identifying genes necessary for re-establishing ion homeostasis and protecting the 
plant from stress damage, as well as those involved in metabolism and plant development under salt stress. Also demonstrated was the ability of $K$. virginica seedlings to sequester sodium, primarily in the roots. In another example, a dehydration and abscisic acid (ABA) induced transcription factor was functionally characterized in Craterostigma plantagineum, a plant possessing the ability to survive complete dehydration.

The knowledge gained from high-throughput sequencing (HTS) technologies and comparative studies of halophytes, coupled with our continually expanding knowledge of metabolites, and the molecular and physiological responses to abiotic stresses that are profiled within this chapter, will allow a plethora of opportunities for directed genetic engineering and breeding strategies that will allow us to meet the worlds demand for food despite a growing population. This chapter aims to offer insights from the past decade of plant abiotic stress research, and give an overview of the wealth of knowledge generated by the genomics era, such as advances from global gene expression surveys and differential gene expression between stresses.

\section{Salt}

Increasing salinity of soil leads to reduction of crop yields, and while soil salinity is not uncommon (Flowers et al., 1997), secondary effects such as irrigation-induced salination affects about $20 \%$ of the world's cultivated fields (Yeo, 1998) with $50 \%$ of lands predicted to be affected in the coming decades. These irrigated lands currently produce an estimated one-third of the world's food (Munns 2002). Irrigation water typically contains a variety of ions, such as $\mathrm{Ca}+, \mathrm{Mg}+$, as well as $\mathrm{Na}+$ in the form of $\mathrm{NaCl}$. It is when the water evaporates and the $\mathrm{Ca}+$ and $\mathrm{Mg}+$ precipitate that the $\mathrm{Na}+$ ions begin to become dominate in the soil (Serrano et al., 1999). Plants do not have specific mechanisms for the uptake of $\mathrm{Na}+$ ions; however several pathways exist for passive entry. For example, root cells uptake $\mathrm{Na}+$ ions via cation channels, of which there are two main classifications. Voltage dependent channels, namely the $\mathrm{K}+$ transporter $H K T 1$, import $\mathrm{Na}+$ ions into root cells (Na+ leakage), ultimately leading to higher concentrations of intracellular sodium. Excess salt in the soil now begins to present an issue due to this osmotic gradient, as elevated $\mathrm{Na}+$ levels in the soil begins to drive water out of the cell. Initial plant response to salt stress, the osmotic stress component, share metabolic similarities with drought however long-term exposure introduces the ion toxicity component, the displacement of $\mathrm{K}+$ ions with $\mathrm{Na}+$ and $\mathrm{Cl}$ - ions. Plants differ in their methods of coping with $\mathrm{Na}+$ entry: some prevent or minimize entry altogether (at the roots), while others reduce the cytoplasmic $\mathrm{Na}+$ concentration by compartmentalization in the vacuoles, thus avoiding toxic effects on photosynthesis and other key metabolic processes (Chaves et al., 2009).

$\mathrm{Na}+$ transport from roots to stem is quite rapid due to the transpiration stream in the xylem, and can only be returned to the roots via the phloem. The roots are able to regulate $\mathrm{Na}+$ levels by export to either the stem of back to the soil; however once in the xylem the $\mathrm{Na}+$ ions will accumulate as the leaves age and the water evaporates (Tester et al., 2003). This rapid accumulation of sodium ions has several detrimental metabolic effects to the plant cell.

Turgor pressure is necessary in order to stretch the cells walls during growth. When faced with the initial sudden influx of $\mathrm{Na}+$ ions, the plant cell is able to sequester these ions in the vacuole, in effect reducing the osmotic potential in an attempt to restore homeostasis and equally importantly reducing degradation of cytosolic enzymes. Research (Carden et al., 
2003) comparing ion concentrations in the roots of two barley (Hordeum vulgare) varieties differing in $\mathrm{NaCl}$ tolerance indicated the cytosolic $\mathrm{Na}+$ concentration requirements to be quite low; around 10-30mM. Na+ concentration within the vacuoles however, may be much higher.

During the initial osmotic phase of salt stress response, the expansion rate of growing leaves is reduced, along with stomatal aperture in response to leaf turgor decline, leading to decreased emergence of new leaves and therefore fewer branches. Among the cereals, barley is the most tolerant with rice (Oryza sativa) being the least tolerant.

$\mathrm{Na}+$ ions also compete with $\mathrm{K}+$ ions for binding sites, often required for crucial cellular and metabolic processes. Protein stability is also coupled with $\mathrm{K}+$ concentration, as it is a cofactor for many enzymes, and the tRNA binding to ribosomes is also dependent on high $\mathrm{K}+$ concentration (Zhu, 2002, Tester et al., 2003). Nutrient uptake from the roots is affected due to $\mathrm{K}+$ ion channels being disrupted, and $\mathrm{Na}+$ induced osmotic changes inhibit root growth.

Another way plants reduce osmotic stress is by the accumulation of cytoplasmic osmolytes such as proline and glyceinebetaine, shown to stabilize the chloroplasts and cellular membranes, as well as play a role in maintaining cell volume and fluid balance (Bohnert et al., 1996). These osmolytes also serve to protect proteins from degradation by reacting oxygen species (ROS). Salt stress (among other abiotic stresses) leads to the accumulation of high levels of ROS. When present at low levels, ROS may act to signal upregulation of the defense-responsive genes. Typically however, excessive production and accumulation of ROS such as hydrogen peroxide $\left(\mathrm{H}_{2} \mathrm{O}_{2}\right)$, superoxide $\left(\mathrm{O}_{2-}\right)$ and hydroxyl radicals $(\mathrm{OH}-)$ can perturb the cellular redox homeostasis leading to oxidative injuries. There is also growing evidence that the cell's downstream ability to repair damage, and scavenge damaging reactive oxygen species (ROS) is equally as important as $\mathrm{Na}+$ uptake and vacuolar sequestration itself. Expression of ROS defense transcripts was found to be elevated in Arabidopsis plants constitutively expressing the zinc finger protein Zat10 (Mittler et al., 2006). The plants displayed enhanced tolerance of salinity, heat and osmotic stress. Surprisingly, knockout and RNAi mutants of Zat10 were also more tolerant to osmotic and salinity stress suggesting that Zat10 plays a key role as both a positive and a negative regulator of plant defenses. Readers are directed toward a recent review (Miller et al., 2008) for a discussion on how ROS integrate cellular signals generated from abiotic stress.

Studies of salt tolerant clones of Eucalyptus camaldulensis, an important crop in Australia due to the use of its oils, have demonstrated a significant increase in shoot proline levels when exposed to $100 \mathrm{mM} \mathrm{NaCl}$ (Woodward et al., 2005). Proline accumulation is known to be mediated by both ABA-dependent and ABA-independent signaling pathways (Hare et al., 1999). Assays on in vitro shoot cultures of Populus euphratica suggest accumulated proline and sugars promote both osmotic and salt tolerance (Watanabe et al., 2000). Another study using sugar beet cultivars (Ghoulam et al., 2001) report a positive trend with proline levels increasing with relation to salt tolerance; however the quantitative contribution of proline to osmotic adjustment in a salt tolerant variety was weak. It was determined the elevation of proline in Arabidopsis, acting as an osmoprotectant during salt stress adaptation, led to the enhancement of the enzymes scavenging reactive oxygen species (Abraham et al., 2003). Recently proline and glycine betaine were shown to improve salt stress in cultured tobacco cells via scavenging of hydrogen peroxide and methylglyoxal (Banu et al., 2010). Glycine betaine was shown to be in induced in the burning bush, Kochia scoparia, (Kern et al., 2004), 
and the Mediterranean shrub Atriplex halimus (Martinex et al., 2004). The cyanobacterium Synechococcus also displays increased tolerance to both salt and cold stress following induction of glycine betaine (Ohnishi et al., 2006).

The second major constraint, besides the osmotic stress of $\mathrm{Na}+$ surrounding the roots, is intracellular $\mathrm{Na}+$ toxicity. Because of the similarity in physicochemical properties between $\mathrm{Na}+$ and $\mathrm{K}+$ (i.e. ionic radius and ion hydration energy), the former competes with $\mathrm{K}+$ for major binding sites in key metabolic processes in the cytoplasm, such as enzymatic reactions, protein synthesis and ribosome functions (Shabala et al., 2008). Increased concentrations of $\mathrm{Na}+$ ions in the soil reduce the activity of many essential nutrients (including $\mathrm{K}^{+}$), making them less available. Secondly, $\mathrm{Na}^{+}$competes with $\mathrm{K}^{+}$for uptake sites at the plasma membrane. Recent evidence indicates the $\mathrm{K}+/ \mathrm{Na}+$ intracellular ratio is a key determinant of salt tolerance. The optimal cytosolic $\mathrm{K}+/ \mathrm{Na}+$ ratio can be maintained by either restricting $\mathrm{Na}+$ accumulation in plant tissues or by preventing $\mathrm{K}+$ loss from the cell. At the cellular level, restricted $\mathrm{Na}+$ uptake, active $\mathrm{Na}+$ exclusion back to the soil solution (via the plasma membrane salt overly sensitive (SOS1) Na+/H+ antiporter; (Zhu, 2002) and compartmentalization of excessive $\mathrm{Na}+$ in the vacuole by the tonoplast $\mathrm{Na}+\mathrm{H} 1+$ exchanger (Zhang and Blumwald 2001) are considered central to salt tolerance.

The past decade of research into the SOS (Salt Overly Sensitive) pathway, utilizing Arabidopsis knock-out mutants and the plants basal tolerance to $\mathrm{NaCl}$ stress as a background concentration for screening, has elucidated key steps in the salt stress signaling pathway (Liu and Zhu, 1998; Ishitani et al., 2000, Qiu et al., 2004). A transient Ca2+ signal, an important secondary messenger for many cellular processes, is ultimately propagated by the secondary messenger IP3 and is the crucial first step in restoring cellular homeostasis. This process involves the sensing of the $\mathrm{Ca}+$ ion by SOS3 (also known as AtCBL4: calcineurin Blike protein) followed by interaction with SOS2, a serine/threonine protein kinase, resulting in its activation (Halfter et al., 2000). These work in conjunction to phosphorylate and activate the transport activity of the plasma membrane $\mathrm{Na}+/ \mathrm{H}+$ antiporter SOS1. SOS1 also has a large cytoplasmic domain predicted to act as potential novel $\mathrm{Na}+$ sensor (Zhu 2002), which may act in feedback regulation. Recent research has indicated the C-terminal region of SOS1 interacts with RCD1 under salt and oxidative stresses (Katiyar-Agarwat et al., 2006). Typically a nuclear protein, RCD1 is found both in the nucleus and in the cytoplasm near the cell periphery during salt and oxidative stresses and demonstrated similar expression and tissue localization as SOS1, perhaps regulating transport of ROS across the cell membrane and oxidative-stress signaling.

There are likely more components to the SOS pathway, the function of which are the focus of current research. For example, there is a family of 9 SO3-like $\mathrm{Ca}+$ binding proteins (the SCaBP's) present in Arabidopsis and 24 SOS2-like protein kinases. One of the SCaBP's, the putative calcium sensor SCABP8/CBL10 was shown to interact with the protein kinase SOS2 to protect Arabidopsis shoots from salt stress (Xie et al., 2009). Further screens under more stringent $(100 \mathrm{mM} \mathrm{NaCl})$ conditions for salt-hypersensitive mutants have yielded more members of the SOS pathway. SOS4 encodes a pyridoxal kinase that is involved in the biosynthesis of pyridoxal-5-phosphate, an active form of vitamin B6, which is often found in roots and necessary for growth (Mahajan et al., 2005). Knock-out mutants for SOS4 are defective in root hair formation and root tip growth, perhaps acting as an integral upstream regulator of root hair development (Zhu et al. 2002). Another component, SOS5, has been shown to be a putative cell surface (Shi et al. 2003) adhesion protein that is required for 
normal cell. For a detailed overview into current insights into the SOS pathway, the reader is directed to the 2008 review by Mahajan.

The SOS pathway is far from a unique response in Arabidopsis, or for that matter glycophytes in general, as conservation of SOS pathway components have been identified in halophytes as well as cereals and also woody periennals. For example in halophytes, salt treatment of Thellungiella halophila led to increased expression of an AtSOS1 homologue in the plasma membrane and increased $\mathrm{H}+$ transport and hydrolytic activity of the H+-ATPase was observed in both the plasma membrane as well the tonoplast (Vera-Estrella et al., 2005). Chenopodium quinoa, a halophyte native to the Andes Mountains, was found to contain 2 AtSOS1 homologs (Maughan et al., 2009), with future work to include complementation of a mutant sos1 Arabidopsis line with the homologues from C. quinoa. Homologues of AtSOS1 have also been identified for multiple glycophyte plant species such as rice (Oryza sativa), the seagrass Cymodocea nodosa, and Populus trichocarpa, the woody perennial poplar tree (Martínez-Atienza et al., 2007, Garciadeblás et al., 2007, Tang et al., 2007, respectively).

Not surprisingly, also conserved are genes controlling sodium entry, such as the previously mentioned K+ channel HKT1 and also genes controlling vacuole compartmentalization, of which the following discussion will focus primarily on AtNHX1, a gene encoding a vacuolar $\mathrm{Na}+\mathrm{H}+$ exchanger. Shi et al., 2002 demonstrated AtNHX1 transcript up-regulation following treatment with $\mathrm{NaCl}, \mathrm{KCl}$ or $\mathrm{ABA}$, as well as detecting strong expression in guard cells and root hairs, suggesting AtNHX1 plays a role in $\mathrm{pH}$ regulation and/ $\mathrm{K}+$ homeostasis along with storing $\mathrm{Na}+$ in the enlarged vacuoles in root hair cells, respectively. As previously mentioned, one way to remove harmful $\mathrm{Na}+$ ions from the cytosol and maintain osmotic balance within the cells is by compartmentalization in the vacuoles, and this aspect of $\mathrm{Na}+$ tolerance has been the focus of much current research, with very encouraging results.

In 1999 Apse et al. demonstrated increased $\mathrm{Na}+$ tolerance from overexpression of the AtNHX1 Na+/H+ antiporter in Arabidopsis, and also that salinity tolerance was correlated with higher-than-normal levels of AtNHX1transcripts, protein, and vacuolar $\mathrm{Na}^{+} / \mathrm{H}^{+}$(sodium/proton) antiport activity. In 2007 tomato (Lycopersicon esculentum cv. Moneymaker) was successfully transformed with an overexpressed AtHKT1, demonstrating not only the ability to grow in $200 \mathrm{mM} \mathrm{Na}+$ concentrations, but an accumulation of sodium ions in the leaves rather than the fruit (Zhang et al., 2001). This discovery was quite exciting in two ways: firstly this yielded the potential for agriculturally relevant crop, as the fruit quality was not adversely affected, and secondly it demonstrated an increased resistance to salt tolerance in an agriculturally important crop plant resulting from the modification of a single trait. Then an AtNHX homologue from a monocot halophyte, Aeluropus littoralis, was identified (AlNHX) and cloned (Zhang et al. 2008). This gene was then transformed into tobacco, which displayed the ability to grow in MS media containing $250 \mathrm{mM} \mathrm{NaCl}$, and survived $400 \mathrm{mM} \mathrm{NaCl}$ in pots for one month. $\mathrm{Na}+$ ions were found to be sequestered primarily in the roots rather than stem tissue, with the leaves maintaining a higher $\mathrm{K}+$ level than the WT control plants. Notably the results indicate the halophyte AlNHX may play a role in root rather than shoot $\mathrm{Na}+$ levels, which was different than observations in overexpressed OsNHX1 in transgenic rice (Fukuda et al., 2004).

In fact there have been many examples of increased salt tolerance resulting from overexpression of the NHX family of $\mathrm{Na}+/ \mathrm{H}+$ antiporters from various plant species, selected examples being: perennial ryegrass transformed with OsNHX1 (Wu et al., 2005), wheat (Xue et al., 2004), Petunia hybrida with AtNHX1 (Xu et al., 2009) demonstrated 
increased salt and drought tolerance. Recently the SsNHX1 gene from the halophyte Salsola soda (Li et al., 2010) conferred salt tolerance when overexpressed in transgenic alfalfa (Medicago sativa). These transgenic alfalfa plants had the ability to grow normally for 50 days under $\mathrm{Na}+$ treatment, with no apparent difference in growth detectable between transgenic plants and wild-type plants under normal conditions, likely due to the use of the stress inducible promoter $\mathrm{rd} 29 \mathrm{~A}$ rather than the typical constitutively active Ca35S promoter. Clearly the NHX family of $\mathrm{Na}+\mathrm{H}+$ of antiporters are able to confer increased $\mathrm{Na}+$ tolerance across a wide range of plant species, and aside from being a single trait, may be even more relevant from a genetic engineering standpoint as sixth-generation soybean plants expressing AtNHX1 proved to be just as resistant (Li et al., 2010) to salt stress as the first generation transgenic plants, indicating this single trait change in heritable.

Although much research has been conducted into the NHX family of $\mathrm{Na}+\mathrm{H}+$ of antiporters, several others have also shown promise for genetic engineering. The plasma membrane $\mathrm{Na}^{\prime \prime} / \mathrm{H}+$ antiporter SOS1, activated it response to salt stresses by the SOS pathway reviewed above, has been shown to be critical for $\mathrm{Na}+$ partitioning in plant organs as well as the ability for the plants to partition $\mathrm{Na}+$ in the stems, preventing the ions to reach photosynthetic tissues (Olias et al., 2009). Ca+ antiporters, such as Arabidopsis $\mathrm{H}+/ \mathrm{Ca} 2+$ Antiporter CAX1 were found to confer increased Ca+ transport and salt tolerance (Chen et al 2004). Both salt and drought tolerance can be significantly increased in Arabidopsis plants by overexpressing AtAVP1, the gene encoding a vacuolar pyrophosphatase which acts as a vacuolar membrane proton pump (Gaxiola et al., 2001), moving more $\mathrm{H}+$ into the vacuoles to create a higher electrochemical gradient. In addition to Arabidopsis, overexpression of AtAVP1 in tomato also enhances drought tolerance (Park et al., 2005), due the increased osmotic adjustment ability conferred by the increased vacuolar $\mathrm{H}+$ concentration.

Gene expression studies in halophytes have yielded fascinating candidate genes for future study; root and leaf tissue collected from Kosteletzkya virginica seedlings (Guo et al., 2008) identified 34 differentially expressed gene fragments homologous to known genes from other species and 4 of novel function. The differentially expressed genes were classified into four groups: those necessary for re-establishing ion homeostasis those involved in metabolism or energy and resuming plant growth and development under salt stress, those involved in regulation of gene expression, and those responsible for signal transduction (Guo et al., 2008).

The halophyte Craterostigma plantagineum, known as the resurrection plant, has the ability to survive complete dehydration. In an attempt to further understand desiccation tolerance in this plant, the CpMYB10 transcription factor gene was functionally characterized (Villalobos et al., 2004) and found to be rapidly induced by dehydration and abscisic ABA treatments in leaves and roots, with no expression detected in fully hydrated tissues. Its subsequent overexpression in Arabidopsis also leads to salt tolerance of the transgenic lines. However, it also was found that plants overexpressing CpMYB10 also exhibited glucose-insensitive and ABA hypersensitive phenotypes. This finding exemplifies an issue in studies with model organisms in short-term laboratory settings: is there overlap between the molecular mechanisms to cope with stress in Arabidopsis, crops plants, and halophytes? Are there overlaps between gene regulation, transcriptional activators, and their tissue-specificity? These distinctions are essential in order for genetic engineering to beneficially be used in crop species for trait selection. One useful tool for candidate gene discovery is genome-wide profiling of both stress-induced expression and post-transcriptional events occurring as a result of stress exposure. 
Recent microarray studies have provided sets of candidate genes for further investigation in order to define the transcriptome profile under salt stress. Tomato (Zhou et al., 2007) gene expression was profiled under salt stress, discovering several key enzyme genes in the metabolic pathways of carbohydrates, amino acids, and fatty acids to be initiated. Also higher transcript levels were detected for antioxidant enzymes, ion transporters, and genes known to be involved with numerous signal transduction pathways. The Euphrat poplar tree (Populus euphratica) that thrives in a saline and arid environment is expanding our understanding of stress induced gene networks in trees, which spend a much greater amount of time in soils due to their longer life and therefore must possess robust systems for dealing with abiotic stresses. Acclimation to increasing levels of $\mathrm{Na}+$ requires adjustment to the osmotic pressure of leaves, achieved by accumulation of $\mathrm{Na}+$ and compensatory decreases in $\mathrm{Ca}+$ and soluble carbohydrates. The primary strategy of $P$. euphratica to protect the cytosol against sodium toxicity is apoplastic, instead of vacuolar, salt accumulation, suggesting that $\mathrm{Na}+$ adaptation requires suppression of $\mathrm{Ca}+$ related signaling pathways. Evidence also points to shifts in carbohydrate metabolism and suppression of reactive oxygen species in mitochondria under salt stress (Ottow et al., 2005). Overexpression of a single $\mathrm{Ca}+$ dependent protein kinase in rice increases salt tolerance (Saijo et al., 2000), with levels of tolerance correlation to levels of protein.

A recent microarray study of $P$. euphratica by Brinker et al. (2010) noted three distinct transcriptome phase changes associated with salt stress, with the duration and intensity of these phases differing between the leaf and root tissues sampled. Key factors initially involved with salinity-stress are molecular chaperones, namely the dehydrins and osmotin, which assist with protein stabilization. Leaves initially suffered from dehydration stress, resulting in transcript level shifts of mitochondrial and photosynthetic genes, indicating adjustment of energy metabolism. Initially a decrease in known stress-associated genes occurs, with induction occurring later, after excessive sodium concentrations accumulate in the leaves. In roots a decrease in aquaporins occurs, potentially reducing water loss. Roots and leaves perceive physiologically different stress situations, and therefore activate unique stress responses; however sucrose synthase and chaperones from leaves were also found upregulated in roots as the only overlapping salt-responsive genes in roots and leaves. To identify the stress-specific genes within the poplar salt-stress responsive transcriptome Brinker et al., used in silico analyses with Arabidopsis orthologs to reduce the number of candidate genes for functional analysis. Ultimately two genes, a lipocalin-like gene and a gene encoding a protein with previously unknown functions were identified and shown to display salt-sensitive phenotypes in Arabidopsis knockout mutants, suggesting these genes play roles in salt tolerance. These results are quite exciting, since they demonstrate saltsusceptible plants harbor genes important for salt tolerance that cannot be identified by conventional salt screens relying on differential gene expression (Brinker et al. 2010).

Foxtail millet (Setaria italica) is a food and fodder grain crop grown in arid and semi-arid regions (Puranik et al., 2011) and is a self-pollinating, diploid, C4 grass. Comparative transcriptome analyses between two cultivars differing in response to short-term salinity stress identified 81 differentially expressed novel transcripts. These transcripts represent an "untapped genetic resource" (Puranik et al., 2011), in a model crop with natural increased resistance to abiotic stress.

High-throughput Illumina based RNA-seq experiments are allowing for genome-wide glimpses into transcript abundance and transcriptional regulation, having the benefit of not 
requiring previously annotated genes or being limited to specific probes present on a microarray. Genome-wide mapping of alternative splicing in Arabidopsis under abiotic stresses (Filichkin et al., 2010) have identified different types of stress differentially regulating known genes implemented in various pathways and cellular responses. For example, a splicing factor in the SR (serine/arginine rich) family, SRP30/SR30 (At1g09140), displays upregulation of the reference isoform under salt stress. This makes SR30 a candidate for further study in order to elucidate salt-stress responses from a splicing factor, rather than a transcriptional angle.

Another Illumina-based RNA-seq experiment using rice (Oryza sativa L. 'Nipponbare) cDNAs focused on the identification of salt-responsive unannotated transcripts derived from root and shoot mRNAs in rice and those transcripts encoding putative functional proteins (Mizuno et al., 2010). 7-day old rice seedlings were transferred to either $150 \mathrm{mM}$ $\mathrm{NaCl}$ solution or water (control) for $1 \mathrm{hr}$. Of the total unannotated transcripts discovered, 1,525 in shoot and 1,659 in root were novel transcripts. Of these transcripts, 213 (shoot) and 436 (root) were differentially expressed in response to salinity stress. The predicted encoded proteins were associated with amino acid metabolism in response to abiotic stresses, and mechanosensitive ion channel function. These responses are gated directly by physical stimuli such as osmotic shock and known to transduce these stimuli into electrical signals. Also captured were previously identified genes involved in salinity tolerance; those associated with trehalose synthesis, dehydrin, ABA synthesis sugar transport, glycerol transferase, and transcription factors similar to those of the DREB family (Mizuno et al., 2010). The DREB transcription activators are involved in ABA-independent and abiotic stress response, binding to the consensus dehydration-responsive element (DRE), present in promoter regions of genes induced by osmotic, saline, and cold stresses (Stockinger et al., 1997). As a substantial number of transcripts were exclusively upregulated only in the root, being directly exposed to 1 hour of salinity stress, it was hypothesized it may take longer exposure time to induce a greater network of genes (Mizuno et al., 2010).

\section{Cold}

Low temperatures, both sudden and for sustained periods, cause dramatic decreases in crop sustainability and yield by affecting the germination and reproductive rate of plants. Low temperature induced cold stress leads to reduced cell expansion and consequently reduced leaf growth, with the loss in turgor pressure causing severe wilting of leaves, ultimately leading to plant death.

Plants differ in their abilities to survive both freezing (temperatures below $0^{\circ} \mathrm{C}$ ) and chilling $\left(0^{\circ} \mathrm{C}\right.$ to around $\left.20^{\circ} \mathrm{C}\right)$ conditions by modifying their physiological and cellular states. The seeds of plants native to latitudes undergoing a freezing winter period such as the winter cereals (certain barley and wheat cultivars, rye, and oats, among others) require a period of cold temperature, called vernalization, prior to germination. This epigenetic response alters the chromatin structure of a flowering repressor gene, in effect allowing the seedlings to "remember" the period of cold preceding the warmth of the growing season (Sung \& Amasino, 2009). The vernalization period is necessary to prevent premature transition to the reproductive phase before the winter freezing threat has ended, however this does not continue past onset of the vegetative phase (Chinnusamy et al., 2007). During the warm growing season, these temperate region plants have little ability to withstand freezing, however as the temperatures gradually fall in the time preceding winter, they are able to 
increase their freezing tolerance by undergoing a phenomenon known as cold acclimation (Thomashow 1999). This results in cell membrane composition and protein concentration changes to reduce intracellular ice crystal formation and dehydration due to freezing (Thomashow, 1998). Plants that do not undergo this gradual acclimation phase have drastically reduced tolerance to freezing. Temperatures of $-5^{\circ} \mathrm{C}$ kill non-acclimated rye yet after a period of gradual exposure to low nonfreezing temperatures the plant is able to survive freezing down to $-30^{\circ} \mathrm{C}$ (Thomashow 1999). Plants native to warmer regions such as the tropics are much more sensitive to chilling and generally lack the ability to acclimatize. Several of these plants are agriculturally important; such as rice, tomato, soybean, grapes, and maize. To this end, efforts have been made to increase freezing tolerance of these plants by combinations of transgenic and conventional breeding approaches, which will be discussed in more detail later.

Much research in the past decade has been directed towards dissecting the mechanisms by which plants initially sense low temperature to subsequently activate the cold-acclimation response, along with regulation by transcription factors, post-transcriptional modifications, secondary messengers, and cross-talk with other stress responses at stress response "nodes". Research has focused on the identification of freezing-tolerance genes through microarray, high-throughput sequencing, and genetic approaches such as comparative studies of freezing-tolerant cultivars. Much information has been yielded thus far, however the story is far from complete. The following section of this chapter will initially provide an overview of the physiology and mechanisms causing freezing injury to the plant, work through our current understanding of the subsequent response pathway(s) and the players involved, before concluding with examples of genetic engineering for improved freezing tolerance and how the genomics era will continue to yield further insight into this multifaceted field. Our understanding of the cold response pathway and the roles of the genes involved is continually improving, and ultimately this will allow for directed single gene modification at multiple steps of the pathway, allowing for enhanced crop improvement.

There are two types of physiological changes a plant must confront upon the onset of cold temperatures: osmotic stress from low non-freezing temperatures and severe membrane damage from freezing. Chilling stress results in ratio changes between fatty acids and proteins as well as decreased membrane fluidity, due to fatty acid unsaturation in membrane lipids (Wang et al., 2006). Chilling also promotes dehydration due to the impairment of water uptake from the roots and a reduction in stomatal closure. Yet by far the largest cause of cold-associated crop loss is membrane damage as a result of freezing, along with the associated intracellular ice crystal formation leading to further dehydration.

Initially ice crystals form in the cell walls and intracellular spaces, decreasing the water potential outside the cell. The unfrozen water within the cell then travels the down the potential gradient, moving out of the cell and towards the intercellular spaces. This dehydration is what leads to the wilting phenotypes of leaf tissue after exposure to freezing temperatures, or in crops as a result of a "cold snap". Colder temperatures result in greater water loss: at $-10^{\circ} \mathrm{C} 90 \%$ of the osmotically active water will move out of the cell into intercellular spaces (Thomashow, 1998). Freeze-induced cellular dehydration also results in a barrage of membrane damage: expansion-induced-lysis, lamellar to hexagonal - II phase transitions and fracture jump lesions (Uemura et al., 1995, Steponkus et al., 1993). Expansion-induced lysis occurs at temperatures around $-2^{\circ}$ to $-4^{\circ} \mathrm{C}$ and is a result of the mechanical damage due to multiple freeze/thaw cycles, where the expansion and contraction of the plasma membrane leads to rupturing (lysing) of the cellular membrane. 
Injury from fracture jump lesions is associated with the occurrence of localized deviations of the plasma membrane fracture plane to closely appressed lamellae (Webb et al., 1994). The cold acclimation process has been shown (Uemura et al., 1995, Steponkus et al., 1993) to prevent both expansion induced lysis and the formation of hexagonal II phase lipids in rye and other plants.

Multiple mechanisms are involved in the stabilization of the plant cell membrane. The content and composition of polar lipids and fatty acids in tomato (Lycopersicon esculentum) at $6^{\circ} \mathrm{C}$ suggests maintenance of high levels of chloroplast membrane lipids play an important role in the survival of cold-tolerant plants (Novitskaya et al., 2000). The Arabidopsis dSFR2 protein also compensates for changes in organelle volume and stabilizes the chloroplast membranes during freezing (Moellering et al., 2010).

The accumulation of sucrose and related simple sugars correspond with cold acclimation, quite likely contributing in part to the stabilization of plant plasma membranes. Investigation of sucrose metabolizing enzyme activity and sugar content during cold acclimation of perennial ryegrass (Lolium perenne) found that the sucrose metabolizing enzymes: phosphate synthase, sucrose synthase and sucrose phosphate synthase are similarly regulated by cold acclimation (Bhowmik et al., 2006). In Arabidopsis, sucrose was found to have a regulatory role in the acclimation of whole plants to cold, likely also playing an important role during diurnal dark periods (Rekarte-Cowie et al., 2008).

In addition there is emerging evidence that certain novel hydrophilic and LEA (late embryogenesis abundant) polypeptides also participate in the stabilization of membranes against freeze-induced injury, where disordered plant LEA proteins act as molecular chaperones (Kovacs et al., 2008). The level of expression of the winter barley LEA abscisic acid-regulated gene HVA1 accumulates upon cold acclimation, before disappearing 2 hours post exposure, with greater expression in the lesser of freezing-resistant cultivars (Sutton et al., 1992). Accumulation of chloroplast LEA proteins is correlated with the capacity of different wheat and rye cultivars to develop freezing tolerance (Dong et al., 2002). Transgenic Arabidopsis expressing a wheat LEA gene displays significant increases in freezing tolerance in cold-acclimated plants. Arabidopsis Cor15am is a late embryogenesis abundant (LEA) related protein shown to exhibit cryoprotective activity in vitro, likely by preventing protein aggregation (Nakayama et al., 2008). Global expression profiles of rice genes under abiotic stresses (Rabbani et al., 2003) using microarrays found an upregulation of LEA proteins post-stress. Genome-wide analysis of LEA proteins in Arabidopsis identified 51 LEA protein encoding genes in the having ABA and/or low temperature response elements in their promoters and, thus induced by ABA, cold, or drought (Hundertmark et al., 2008). The majority of LEA proteins were predicted to be highly hydrophilic and natively unstructured, but some were predicted to be folded. This comprehensive analysis will be an important starting point for future efforts to elucidate the functional role of these proteins (Hundertmark et al., 2008).

Plant cells initially sense cold stress resulting from the change in the fluidity of the cellular membrane. Cellular membranes are inherently dynamic, and cytoskeleton re-organization is an integral component in low-temperature signal transduction. The cold acclimation process is associated with gene expression requiring a transient influx of $\mathrm{Ca}+$ from the cytosol. Under normal conditions the influx of $\mathrm{Ca}+$ at $4 \mathrm{C}$ is nearly 15 times greater than at $25 \mathrm{C}$, but when treated with chemical agents causing an increased $\mathrm{Ca}+$ influx, cold acclimatizationspecific genes are expressed at higher temperatures (Monroy \& Dhindsa, 1995). When alfalfa (Medicado sativa) cells are treated with chemicals blocking this influx (Ovar et al., 2000), they 
are unable to cold-acclimatize. Furthermore Ovar et al. demonstrated the activation of coldacclimation genes, $\mathrm{Ca}+$ influx, and freezing tolerance at $4 \mathrm{C}$ to all be prevented by membrane stabilization, yet induced at $25 \mathrm{C}$ by the addition of an actin microfilament destabilizer, thereby linking the membrane rigidification process to the influx of $\mathrm{Ca}+$ necessary to signal cold acclimation genes. Calcium sensing and sequestering proteins (Komatsu et al., 2007), and phosphoinositides also play roles as signaling molecules in the cold-stress pathway. Phosphoinositides are signaling molecules that regulate cellular events including vesicle targeting and interactions between membrane and cytoskeleton, and accumulate in salt, cold, and osmotically stressed plants (Williams et al., 2005). Mutations in the Arabidopsis phosphoinositide phosphatase gene SAC9 lead to overaccumulation of phosphoinositides and confer the characteristics of a constitutive stress response, including dwarfism, closed stomata. The mutations also upregulate stress-induced genes and overaccumulate ROS.

Accumulation of ROS $\left(\mathrm{O}_{2^{-}}, \mathrm{H}_{2} \mathrm{O}_{2}\right.$, and $\left.\mathrm{HO}\right)$ as secondary signals has strong impacts on plants ability to withstand cold. Once thought to only be an un-wanted byproduct of aerobic metabolism upregulated under biotic and abiotic stresses, ROS are now known to act as key regulators in numerous biological processes (Miller et al., 2008). An Arabidopsis mutant defective in the respiratory electron chain of mitochondria (frostbite1) constitutively produces ROS and displays reduced cold induction of stress-responsive genes such as RD29A, KIN1, COR15A, and COR47. The leaves also have a reduced capacity for cold acclimation, appear water-soaked, and leak electrolytes (Lee et al., 2002).

Hormones are also implicated in the response of plants to environmental stresses. The polyamine putrescine also progressively increases upon cold stress treatment and likely acts as regulator of hormone biosynthesis (Cuevas et al., 2008). Loss of function mutants and reverse complementation tests indicated that putrescine also modulates ABA biosynthesis at the transcriptional level in response to low temperature. Hormonal levels drive cell division and expansion and the plant hormone auxin is a key regulator of virtually every aspect of plant growth and development. Auxin plays a major role in cell expansion and growth, as well as being quite sensitive to temperature changes (Gray et al. 1998). Root growth and gravity response of Arabidopsis after cold stress suggests that cold stress affects auxin transport rather than auxin signaling (Shibasaki et al., 2009). Additionally, cold stress differentially affects various protein trafficking pathways, independently of cellular actin organization and membrane fluidity. Taken together, these results suggest that the effect of cold stress on auxin is linked to the inhibition of intracellular movement of auxin efflux carriers (Shibasaki et al 2009).

In 1991 Johnson-Flanagan et al. demonstrated increased freezing tolerance of Brassica napus suspension-cultured cells by the addition of the herbicide mefluidide or ABA to the culture medium. In 2000 Llorente et al. showed that ABA is required for full development of freezing tolerance in cold-acclimated Arabidopsis, and plays a role in mediating constitutive freezing tolerance. The Arabidopsis mutant frs1 (freezing sensitive 1) is deficient in an allele of the ABA3 locus, displaying reduced constitutive freezing tolerance as well as tolerance post cold acclimation, producing the wilty phenotype corresponding with excessive water loss. Upon receiving an exogenous ABA treatment, frs1 plants recover both their wild-type phenotype and capability to tolerate freezing temperatures and retain water. Gene expression in the frs1 mutants was also altered in response to dehydration, suggesting dependence on ABA-regulated proteins allowing plants to cope with freeze-induced cellular dehydration (Llorente et al., 2000). Not all genes induced by low temperature are ABAdependent, as evidenced by some of transcriptional regulators mentioned in the following 
section and indicative of the complexity and crosstalk of the regulatory network. Recent genome-wide profiling studies have begun to identify further downstream transcription factors and gene targets resulting from both pathways. In the ABA-dependent pathway, ABA likely activates the bZIP (basic leucine zipper) transcription factors, which regulate ABA dependent COR (COld Regulated) genes through ABA-responsive elements (ABRE) promoters. In the ABA-independent pathway, low temperature triggers the expression of the CBF family of transcription factors, which in turn activate downstream COR genes with other specific motifs in their promoters (Thomashow, 1999). There is also evidence (Knight et al., 2004, Talanova et al., 2008) of ABA initiating CBF expression although at lower levels than those resulting from cold acclimation. Both of these pathways confer or enhance freezing tolerance in plants and are described in more detail below.

The CBF cold response pathway plays a central role in cold acclimation and has been the focus of intense research for the past 2 decades. The CBF/DREB (C-repeat-binding factor/dehydration responsive element-binding factor) genes encode a small family of transcriptional activators that play an important role in freezing tolerance and cold acclimation (Thomashow 1999). In Arabidopsis there are three members CBF1-3 (also known as DREB1-B, C, and A, respectively), with transcripts beginning to accumulate within 15 minutes after exposure to cold temperatures. A microarray experiment to determine the core set of cold-induced genes in Arabidopsis (Vogel et al., 2005) found 302 genes to be upregulated upon cold stress, with $85 \%$ of these assigned to the CBF2 regulon and also induced upon CBF2 overexpression. The CBF proteins bind to the CRT/DRE motif (CCGAC) present in the promoters of a number of COR genes named the CBF regulon, which imparts freezing tolerance by activating the COR genes, with CBF induction occurring by ICE1 (Inducer of CBF Expression 1).

ICE1 was identified (Chinnusamy et al., 2003) as an upstream transcription factor regulating transcription of CBF genes in the cold. ICE1 encodes a MYC-like bHLH transcriptional activator that binds the CBF3 promoter. In Arabidopsis the ice1 mutation blocks the expression of CBF3 as well as decreases the expression of genes downstream of CBFs, leading to a significant reduction in plant chilling and freezing tolerance. It is also constitutively expressed at low levels, and its overexpression in wild-type plants enhances the expression of the CBF regulon in the cold and improves freezing tolerance of the transgenic plants. ICE2, another bHLH transcription factor and homologue to ICE1, confers decreased levels of carbohydrate and increased levels of lipids when overexpressed in Arabidopsis (Fursova et al., 2008). CBF1 displayed differential expression in transgenic plants compared to wild-type control plants, suggesting a regulatory role provided by ICE2. HOS1 is negative regulator of ICE1, mediating its ubiquitination and subsequent degradation both in vitro and in vivo (Dong et al., 2006). Overexpression of HOS1 represses expression of the $C B F$ s and their downstream genes, conferring increased sensitivity to freezing stress.

SIZ1, a SUMO E3 ligase, is a positive regulator of ICE1 and the sumoylation of ICE1 may activate and/or stabilize the protein, facilitating expression of CBF3/DREB1A and repression of MYB15, leading to low temperature tolerance (Miura et al., 2007). Arabidopsis knockouts siz1-2 and siz1-3 cause freezing and chilling sensitivities indicating that the SIZ1 is a controller of low temperature adaptation in plants. Interestingly a protein associated with stomatal differentiation, SCREAM, was shown to in fact be ICE1 (Kanaoka et al., 2008). This creates a potential link between cold acclimation and stomatal differentiation and a basis for future research. 
All three CBF genes do not play the same roles in freezing tolerance. The function of CBF2 was not only demonstrated as having a distinct function from CBF1 and CBF3, but was shown to be a negative regulator of their activity. Reverse genetic approaches using an Arabidopsis knockout mutant for CBF2 displayed an increased capacity to tolerate freezing both before and after cold acclimation, and the plants displayed increased tolerance to dehydration and salt stresses (Novillo et al., 2004). The mutants also had stronger and more sustained expression of CBF/DREB1-regulated genes, resulting from increased expression of $\mathrm{CBF} 1$ and $\mathrm{CBF} 3$ in the $c b f 2$ plants, with the authors suggesting CBF1/CBF3 induction to precede $\mathrm{CBF}$ 2. Indeed, DNA motifs for the calmodulin binding transcription activator (CAMTA) family of transcription factors have been identified in the promoters of CBF2, as well as the transcription factor ZAT12, conferring both negative and positive regulation. One of these binding sites (CAMTA), was shown to be a positive regulator of CBF2 expression, with mutant plants impaired in freezing tolerance. CAMTA proteins may play a role in cold acclimation by linking $\mathrm{Ca}+$ and calmodulin signaling with expression of $\mathrm{COR}$ genes (Doherty et al., 2009). Both ICE1 and CAMTA binding sites are found in the promoter of $\mathrm{CBF} 2$, potentially directly linking $\mathrm{Ca}+$ signaling to cold response.

Low temperature induction of the Arabidopsis CBFs is also gated by the circadian clock (Fowler et al., 2005) with the highest and lowest levels of cold-induced CBF1-3 transcript occurring at 4 and $16 \mathrm{~h}$ after subjective dawn, respectively. Other transcription factors induced by cold in parallel with CBF1-3 are also gated by the circadian clock; however cycle in the opposite phase. This suggests nonidentical, though potentially overlapping, signaling pathways. Similar results in wheat (Badawi et al., 2007) and tomato (Pennycooke et al., 2008) suggest circadian regulation under homeostatic conditions concurring with dawn and dusk periods, maybe overlapping with stomatal aperture changes.

Light is also implicated in regulating the CBF pathway, for instance a low red to far-red ratio of light is sufficient to increase $\mathrm{CBF}$ gene expression and confer freezing tolerance at temperatures higher than those required for cold acclimation (Franklin et al., 2007), providing evidence for a second temperature-regulated step in this pathway. PhytochromeInteracting Factor7 (PIF7) functions as a transcriptional repressor for DREB1C (CBF2) expression and its activity is regulated by components of the red light photoreceptor, and circadian oscillator (Kidokoro et al., 2009). DREB1/CBF expression may be important for avoiding plant growth retardation by the accumulation of DREB1/CBF proteins under unstressed conditions (Kidokoro et al., 2009). Downregulation occurs through a complex network of transcription factors, such as ZAT12 downregulating CBF2 (Vogel et al., 2005), and MYB15 interacting with ICE1, subsequently binding to the MYB recognition sequences in the CBF promoters (Agarwal et al., 2006)

The CBF pathway is not only present in dicots such as Arabidopsis, but is widespread through monocots and multiple plant genera, including those native to warm regions and not inherently cold tolerant, with variation in CBF gene copy numbers (Qin et al., 2004, Skinner et al., 2006, Badawi et al., 2007, Stockinger et al., 2007, Tamura et al., 2007, , Pennycooke et al., 2008, Knox et al., 2010). A recent paper by one of the pioneers of the field presents a detailed overview of the status of CBF research today (Thomashow, 2010)., and readers wishing for further detail are directed to this review

Alternative cold tolerance pathways also initiate transcription of cold-responsive genes, for example Arabidopsis SFR2 encodes a novel $\beta$-glycosidase, contributing to freezing tolerance and distinct from the CBF pathway (Thorlby et al., 2004). The null mutant (sfr2-1) causes 
freezing sensitivity in Arabidopsis possibly due to electrolyte leakage. Homologous genes are present and expressed in many terrestrial plants, including those unable to tolerate freezing. Each of these homologues however, has the ability to complement the freezing sensitivity of the Arabidopsis sfr2 mutant (Fourrier et al., 2008). In Arabidopsis the SFR2 protein is localized to the chloroplast outer envelope membrane, with the chloroplasts of the sfr2 mutant displaying rapid damage post-freezing.

MYBS3 is a single DNA-binding repeat MYB transcription factor previously shown to mediate sugar signaling in rice and also indicated to play a novel role in cold adaptation $(\mathrm{Su}$ et al., 2010). Transgenic rice constitutively overexpressing MYBS3 displayed no yield penalty in normal field conditions while tolerating temperatures of $4^{\circ} \mathrm{C}$ for at least 1 week. Su et al. demonstrated repression of CBF-dependent signaling by MYBS3 at the transcriptional level, with distinct pathways likely acting in parallel for short- and long-term cold stress in rice. This previously undiscovered cold adaptation pathway adds another layer to the complex web of plant responses to cold stress.

RNA processing and nuclear export / stabilization are critical mechanisms in a plants response to cold stress. Recent research has shown cold shock proteins (CSPSs) play roles in promoting cold tolerance, however much remains to be discovered in order to determine the mechanism in plants to promote cold tolerance. A protein from wheat with homology to an $E$. coli cold shock protein has been linked to the regulation of translation under low temperature; potentially by acting as a RNA chaperone to destabilize secondary structure (Nakaminami et al., 2006). Cold shock domain proteins and glycine-rich RNA-binding proteins from Arabidopsis have been shown to promote cold adaptation process E. coli (Kim et al., 2006). Excitingly, 2 novel cold shock domain proteins were cloned and characterized from rice, a plant unable to cold acclimatize. Nonetheless, in vivo functional analysis confirmed these OsCSPs complement a cold-sensitive bacterial strain that lacks four endogenous cold shock proteins (Chaikam et al., 2008). Transcripts were also shown to be upregulated during temperature decreases. Two structurally differed CSPs of Arabidopsis perform different functions in seed germination and growth under stress conditions, even rescuing cold tolerance from an RNA-binding protein null mutant (Park et al., 2009). Other RNA-binding proteins such as known splicing factors alter expression under cold stress, for example the serine-arginine (SR) rich splicing factor SRP34 (At1g02840), as recently reviewed (Filichkin et al., 2010), displays exon skipping under both drought and cold conditions, with several novel introns predicted through alternative splicing. Alternative splicing of another SR protein, SR1, was reported (Iida et al., 2004) under cold stress, as well as in response to hormones (Palusa et al., 2007). Different isoforms of a splicing factor likely alter the binding preference and spicing of a host of downstream targets, presenting an exciting area for future research. The Arabidopsis STABILIZED1 gene encodes a U5 snRNPassociated splicing factor required for both pre-mRNA splicing and transcript turnover. Of interest, it is also upregulated by cold stress, and the sta1-1 mutant plants are defective in the splicing of COR15A (Lee et al., 2006).

Thanks to the genomics revolution, the role of microRNAs (miRNAs) in abiotic stress regulation is being elucidated. Endogenous miRNA levels change as plants are exposed to abiotic stresses (Sunkar et al., 2004), and readers are pointed towards reviews (JonesRhoades et al., 2006, Sunkar et al., 2007) providing the backstory of miRNA research in plants with regards to stresses and classes of miRNA, A tiling array (Matsiu et al., 2008) global transcriptome analysis of Arabidopsis discovered 7,719 non-AGI (Arabidopsis Genome Initiative) transcriptional units (TUs) in the unannotated "intergenic" regions of Arabidopsis 
genome, and most of these are hypothetical non-protein-coding RNAs. Close to $80 \%$ of the previously un-annotated TUs belonged to pairs of the fully overlapping sense-antisense transcripts, suggesting stress or ABA induction of antisense TUs in the fully overlapping sense. These non-coding small RNAs exhibit stress-responsive expression patterns; however are also implicated in a very broad web of in planta regulation. For example, in wheat (Triticum aestivum) the trans targets of miRNAs include both transcription factors implicated in development and a plethora of genes involved multiple physiological processes (Yao et al., 2010). Further research will be necessary to pinpoint small RNA targets and the effects of their regulation with regards to cold stress, and other stresses.

Transcriptome profiling using microarrays is allowing for the identification of groups and networks of genes that respond to cold stress. A consensus among microarray studies (Fowler and Thomashow 2002, Rabbini et al., 2003, Lee et al. 2006, Oono et al. 2006) is that genes induced by abiotic stress fall into 2 categories: functional proteins such as the aforementioned LEA proteins, proteins playing roles in osmoprotection, and transporters. The second category is the regulatory proteins; the transcription factors, kinases, phosphatases, and other molecules dealing with signaling, directly or indirectly, such as those of the MAP kinase cascade. Such broad profiling allows for glimpses into regulatory networks and offers the potential for further research into specific up or down-regulated genes or gene families.

Initial work into engineering for cold tolerance focused on the CBF transcription factors. It was initially shown that overexpression of AtCBF3 in Arabidopsis confers freezing and drought tolerance, however also causes a dwarf phenotype (Liu et al., 1998). In comparison when AtCBF3 is overexpressed in rice, which is unable to cold acclimate, increased tolerance to drought and high salinity stress (and not low-temperature) without stunting growth results (Oh et al., 2005). Readers are directed towards a recent review (Thomashow, 2010) for further insights gained from the CBF pathway in genetic engineering.

Rice is a staple food in much of the world and the seedlings are particularly sensitive to chilling in high-elevation areas. Much research has been conducted into enhancing the cold tolerance of rice to allow for growth in different geographic regions to increase production. Recently ( $\mathrm{Hu}$ et al., 2008) isolated SNAC2, a nuclear stress-responsive NAC gene from upland rice (Oryza sativa L. ssp japonica) characterized for its role in stress tolerance. Transgenic plants overexpressing SNAC2 had higher cell membrane stability than wild type during cold stress with over half of the transgenic plants, and none of the WT plants, surviving after 5 days at $4 \mathrm{C}$ (Hu et al., 2008). Another transcription factor, OsMYB3R-2, functions in both stress and developmental processes in rice, with transgenic rice plants overexpressing OsMYB3R-2 shown to exhibit enhanced cold tolerance by regulating the progress of the cell cycle during chilling stress (Ma et al., 2009), suggesting cell cycle regulation as possible resistance mechanism to stress.

Molecules involved in the $\mathrm{Ca}+$ signaling pathway, acting upstream of transcription factors, can also enhance cold tolerance. Over-expression of a calcium-dependent protein kinase and a calreticulin interacting protein has been shown to enhance cold tolerance in rice plants, emphasizing the importance of signaling components in the response to cold stress in rice (Komatsu et al., 2007). As mentioned in the salt section, overexpression of a single $\mathrm{Ca}+$ dependent protein kinase in rice increases cold tolerance (Saijo et al., 2000), as well as salt tolerance, indicative of the crosstalk between abiotic stress response pathways.

Research into ethylene response factor (ERF) proteins is demonstrating their roles in plant stress responses via interaction with DRE/CBF genes, yet the regulatory mechanism is not well elucidated. Overexpressing TERF2/LeERF2 in tobacco not only activates expression of 
cold-related genes, but reduces electrolyte leakage (Zhang et al., 2010). The authors demonstrated RNAi knockdown TERF2/LeERF2 transgenic lines to have reduced freezing tolerance, rescued to normal levels with treatment of a precursor to ethylene. Overexpression of OsTERF2 in rice enhanced cold tolerance without affecting growth or agronomic traits (Tian et al., 2010). The transgenic lines displayed increased accumulation of osmotic substances and chlorophyll, as well as reduced ROS and decreased electrolyte leakage. The overexpression of OsTERF2 was shown to initiate expression of downstream cold regulated genes such as OsMyb, OsICE1, and OsCDPK7.

Our understanding of the cold response pathway has thus far allowed for single trait genetic engineering to improve or alter cold tolerance, often with very promising results however not without the caveats present in most abiotic stress research, such the differences between monocots and dicots. The traditional model system is the dicot Arabidopsis, and as evidenced by the OEX CBF growth phenotype differences between Arabidopsis and the monocot rice, homologous genes don't always confer conserved responses. The recent development of molecular, genetic, and genomic resources for the grasses Brachypodium distachyon, Setaria italica, and Setaria viridis provide model platforms for future studies of cold, and other abiotic stress research in general, in monocot systems.

\section{Severe desiccation and water deficit: heat and drought stress}

Plants face additive and interacting responses to drought and heat stress such as water loss through the evapotranspiration resulting from the opening of stomata for heat dissipation, and detrimental alterations to photosynthesis. There are subsets of genes that are induced by a combination of heat and drought stress that are not induced by each stress independently, as in a laboratory growth chamber. Under field growing conditions resulting in limited water supply, crop plants would be exposed to both stresses simultaneously. Therefore heat and drought stresses will be profiled in the same overarching section, and will have an additional portion at the end focusing on the overlap and further insights into the crosstalk present between these networks.

\subsection{Heat stress}

A transient elevation in temperature, $10-15 \mathrm{C}$ above ambient, is typically defined as heat stress (Wahid et al., 2007); however the effects vary with the duration and amount of temperature increase. Plants differ in their abilities to cope with rising temperatures; corn and rice are more thermotolerant than wheat, for example. As with all stresses, the onset of heat immediately changes the cellular state, alters membrane fluidity and lipid composition, and initiates the signaling cascades that ultimately lead to transcript accumulation for genes encoding protective and chaperone activities. The following section will profile the cellular changes that occur post-heat stress, with emphasis on how genetic engineering is utilizing these response mechanisms to both elucidate the stress response network and improve heat tolerance in agriculturally important crop species. For a detailed overview of plant heat tolerance, readers are directed to the aforementioned review by Wahid et al. (2007).

Gradual nonlethal heat treatment confers a phenomenon known as thermotolerance; an increase in heat resistance over non-acclimated plants similar in principle to the cold acclimation detailed in the previous section, however mechanistically different and fully elucidated. What is understood however, is genetic manipulations of some aspects of the 
response pathway are able to confer single trait heat tolerance to the resulting transgenic plants. Such advances and insights thus far are profiled in the following section.

Engineering for tolerance encompasses many facets of the cells natural defense mechanisms to stress, such as reducing the damaging effects of oxidative stress and subsequent buildup of ROS during heat (and other abiotic stresses). Transgenic potato plants were generated containing both the superoxide dismutase (SOD) and ascorbate peroxidase (APX) genes encoding two key chloroplast enzymes for ROS detoxification under the control of the chloroplast SWPA2 oxidative stress-inducible promoter (Tang et al., 2006). Under high temperature treatment, the transgenic plants displayed a photosynthetic activity decrease of only $6 \%$, whereas wild-type plants displayed a $29 \%$ decrease. These results suggest that manipulation of the antioxidative mechanism is likely a valuable tool for the creation of heat tolerant crop plants.

The osmolyte glycinebetaine (mentioned earlier in the section on salt) has been implicated in heat tolerance, although the exact mechanism though which tolerance is gained remains unknown. Tobacco (Nicotiana tabacum) lines transgenically accumulating glycinebetaine display higher thermotolerance than WT plants, especially when heat stress occurs under light, suggesting that the accumulation of glycinebetaine leads to increased tolerance to heat-enhanced photoinhibition. This tolerance is likely achieved by accelerating repair of photosystem II (PSII), possibly due to the reduced accumulation of ROS in the transgenic plants with elevated levels of glycinebetaine (Yang et al., 2007). Isoprene is a volatile compound emitted from leaves of many plant species, and has also has been implemented in heat tolerance. Recently the Populus alba isoprene synthase gene was introduced into Arabidopsis and shown to confer elevated heat tolerance in the transgenic lines over wild type (Sasaki et al., 2007).

As with chilling stress, it is becoming evident that heat stress promotes fatty acid unsaturation in membrane lipids, altering the ratio between membrane fatty acids and proteins and resulting in membrane fluidity changes. Protein transfer across membranes is mediated by protein machinery embedded in the membrane, with different lipid classes within a membrane is known to influence the efficiency of some protein translocation processes (Ma et al., 2006). To this end, membrane associated proteins involved in lipid metabolism have been successfully utilized to increase thermotolerance in both model and crop plants. Fatty acid omega-3 desaturase (FAD) is the key enzyme catalyzing the formation of trienoic fatty acids, the most common fatty acids in membrane lipids, comprising $70 \%$ of the membrane lipids in the chloroplast and implemented with defense response (Yaeno et al., 2004).

By investigating transgenic tobacco plants with reduced trienoic fatty acid content (Murakami et al., 2000) it was revealed that decreased contents of trienoic fatty acids play an important role in high-temperature tolerance. Transgenic rice plants in which the content of dienoic fatty acids was increased were more tolerant to high temperatures than WT, having increases in both chlorophyll content and growth. The maximum photochemical efficiency of PSII was also higher in transgenic plants plants upon high temperature stress (Sohn et al., 2007). Recently, antisense expression of tomato chloroplast omega-3 fatty acid desaturase gene (LeFAD7) was demonstrated to enhance hightemperature tolerance, again through reductions of trienoic fatty acids and increases of dienoic fatty acids (Liu X. et al., 2010).

Photosynthesis, the light driven carbon dioxide assimilation process and the primary means of energy production in plants, is extremely sensitive to elevated temperatures. 
Heat stress inhibits photosynthesis in part by reducing the activation of Rubisco, due initially to the denaturation of Rubisco activase (Salvucci et al., 2001). Loss of activase activity during heat stress is caused by exceptional sensitivity of the protein to thermal denaturation and is responsible in part for deactivation of Rubisco itself. The effects of heat stress on Arabidopsis plants in which Rubisco activase or chloroplast thylakoid membrane fluidity had been altered demonstrated that a) plants having less polyunsaturation of thylakoid lipids display lower net photosynthetic rates than the WT and $b)$ the rate of Rubisco deactivation affects the temperature dependence of photosynthesis (Kim et al., 2005). To test the hypothesis that a non-degraded Rubisco activase can improve photosynthesis under elevated temperatures, several thermostable Arabidopsis isoforms of Rubisco activase were introduced into a Rubisco activase null mutant line. The transgenics displayed higher photosynthetic rates, with increased biomass and increased seed yields, compared to wild-type activase, providing evidence for Rubisco activase as a limiting factor in photosynthesis elevated temperatures (Kurek et al., 2007). Rubisco activase is a potential target for future genetic manipulation in improving crop plants productivity under heat stress (Kurek et al., 2007). In addition, down-regulation of photosynthesis in temperature stressed plants is caused by reduced post-translational import into the chloroplast of plastidic proteins required for the replacement of impaired proteins coded by the nuclear genome (Dutta et al., 2010).

Heat stress also inhibits synthesis and promotes degradation of cytokinins, important hormones for regulation of growth and development processes, such as cell division, leaf senescence, and root growth (Xu et al., 2010), however the underlying mechanisms are poorly understood. Xu et al. used transgenic Agrostis stolonifera, a C3 perennial grass species, to survey protein changes in response to elevated temperatures. The gene controlling cytokinin synthesis was used to create 2 transgenic lines, each with different inducible promoters, and a null mutant line. Protein content changes in leaf and root tissue were found to primarily regulate energy metabolism, protein destination and storage. In the transgenic lines, 6 leaf proteins and 9 root proteins were found to be elevated or remain at steady state comparable WT levels, and among these was the small subunit of Rubisco, Hsp90, and glycolate oxidase, a suggesting a definite regulatory role for cytokinins in metabolic pathway regulation associated with heat tolerance in C3 perennial grass species (Xu et al., 2010).

Much research has been conducted on heat shock proteins (HSPs), the molecular chaperones regulating proper protein folding, localization, degradation, and stabilization of under homeostatic and stress conditions (Feder et al., 1999). There are several families of HSPs present in both plants and animals, named based on their respective molecular weights. There are 5 classes of HSPs in plants (for comprehensive reviews see Baniwal et al., 2004, Wang et al., 2004, Kotak et al., 2007); the Hsp70 class which prevents protein aggregation and assists with transcriptional activation and import, the Hsp60 chaperonin class which assists with folding and re-folding, the Hsp90 class which plays a role in assisting other signaling molecules, the Hsp100 class preventing unfolding, and finally the sHSP class which act to stabilize non-native proteins (Figure 2). Much of our current knowledge regarding HSPs contribution towards plant survival under heat stress is based off homology with other eukaryotes and extrapolation based molecular chaperoning activity and in vitro, with little specific in vivo information (Kotak et al., 2007). 


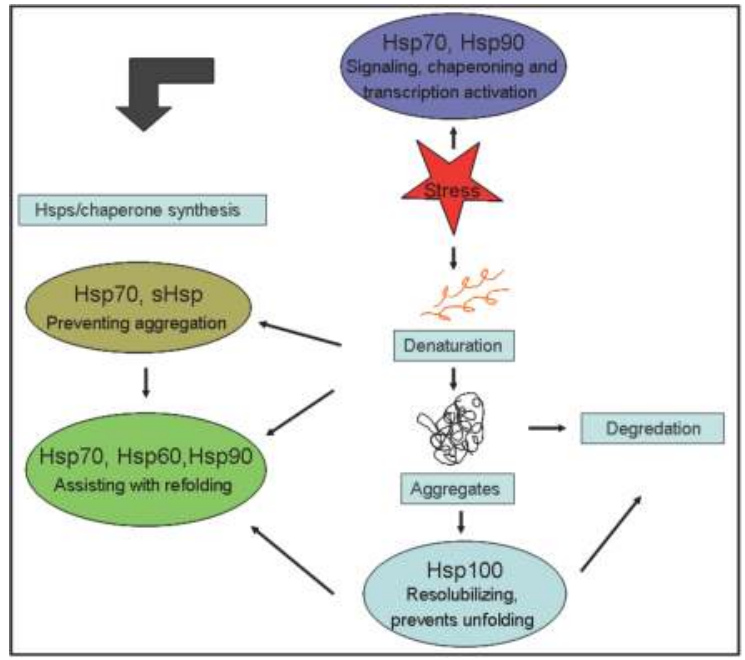

Fig. 2. Heat shock protein (Hsp) network during abiotic stress response, preventing protein degradation and assisting with maintaining cellular homeostasis. (Figure adapted from Wang et al., 2004)

In the absence of heat shock, cytosolic HSP90 appears to negatively regulate heat-inducible genes by actively suppressing Hsp function, however in is transiently inactivated following heat shock, leading to Hsf activation (Yamada et al., 2007). AtHsp101, when constitutively expressed in rice, enhances thermotolerance (Katiyar-Agarwal et al., 2003).

It is the heat stress transcription factor (Hsf) family of more than 20 members, which are the central regulation proteins of heat stress response and defense (Baniwal et al., 2004). These modular classes (A, B, and C) share motifs for DNA binding and transcriptional activation, and are defined by differences in the hydrophobic amino acid residues required for oligomerization. The B and C class Hsfs are believed to function in conjunction with class A Hsfs to amplify or regulate signals, rather than function on their own. The majority of our knowledge into the mechanisms into plant Hsfs has come from studies with 2 dicots: Arabidopsis and tomato (Figure 3).

Tomato has 17 members of the Hsf family, however despite this complexity; HsfA1 has a unique function as being the "master regulator" for induced thermotolerance and cannot be replaced with any of the other Hsf members (Mishra et al., 2002). This is not the case in Arabidopsis however, where sequencing of Arabidopsis genome revealed unique complexity of the Hsf family. Hsfs comprising 21 members were assigned to 3 classes and 14 groups based structural and phylogenetic comparison to homologues in other eukaryotes and plants (Nover et al 2001). No master regulator has been yet identified in Arabidopsis, where even double knockouts only affect a small subset of genes. While offering a beginning for homology comparisons, there is not complete overlap between the Hsfs in tomato and Arabidopsis however, for example while HsfA1a and HsfA1b are highly conserved between species. In Arabidopsis (unlike tomato) they have the capacity to functionally replace each other. Recent work implicates HsfA1a/1b in cooperation at a number of target gene promoters also regulated by HsfA2, possibly indicating a recruitment of HsfA2 and replacement of HsfA1a/A1b at the same target gene promoters (Li et al., 2010). 


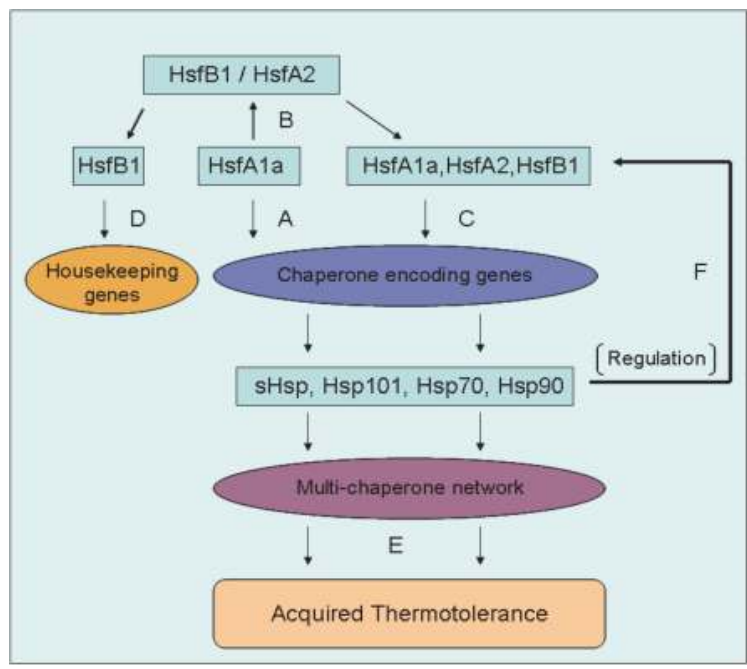

Fig. 3. Current model of the heat stress response pathway in tomato: the interaction of Hsfs and Hsps. A) HsfA1a is the master regulator responsible for induction of heat stress includes gene expression and encoding chaperones (Hsps), along with HsfA2 and HsfB1, next B) HsfA2 forms a hetero-oligomer with HsfA1a to activate Hsp gene expression while C) HsfB1 functions as coregulator of HsfA1a it an enhancesome-like complex by recruitment of the histone acetyl transferase HAC1. Finally, D) heat stress transcription factor (Hsf)B1, in conjunction with other transcription factors, controls expression of housekeeping genes to restore homeostasis. E) The large network of Hsps acting as molecular chaperones are an essential aspect of acquired thermotolerance, while F) the Hsp complexes themselves then modulate the heat shock response by interacting with the Hsfs. Figure adapted from a 2007 review by von Koskull-Doring et al. and references therein.

To date only a few of the Hsfs have been studied in depth, and the following brief summary of the Hsf network comes from an excellent review by von Koskull-Doring et al., from 2007, which readers are encouraged to read for a detailed summary of Hsf structure and function. HsfA2 is the dominant Hsf present in thermotolerant cells in both Arabidopsis and tomato, and may initiate transcription of a core subset of heat stress induced genes. Recent work has also implicated AtHsfA2 in anoxia tolerance in Arabidopsis (Banti et al., 2010), further demonstrating the overlapping and redundancy of this complex network. AtHsfA2 also plays an important role in linking heat shock with oxidative stress signals (Li et al., 2005). A recent study (Cohen-Peer et al., 2010) has demonstrated AtSUMO1 of AtHsfA2 to be involved with the plant's regulatory response to heat stress and acquired thermotolerance. Post-translational modification of target proteins by SUMO proteins (see cold section for background) regulates many cellular processes, and adds a further layer to this complex network In a recent study to identify potential regulatory components involved in thermotolerance, a reverse genetics approach was used by screening Arabidopsis T-DNA insertion mutants for lines displaying phenotypic decreased thermotolerance. The Hsf AtHsfA2 fell out as the only mutant line more sensitive to severe heat stress than WT following long recovery periods, and able to be complemented by the introduction of WT AtHsfA2. This depicts HsfA2 as a heat-inducible transactivator, sustaining expression of 
Hsp genes and extending the duration of acquired thermotolerance in Arabidopsis (Charng et al., 2007), as well as being an attractive candidate for continued research in the orthologous genes of crop plants under field conditions.

LeHsfB1 interacts with HsfA1a in a synergistic fashion to form an "enhanceosome" complex to possibly regulate the expression of housekeeping genes during periods of heat stress. Both tomato and Arabidopsis HsfA5 acts as an inhibitor of the activator HsfA4, by initiating the formation of hetero-oligomer complexes. HsfA9 plays a role in seed development and maturation, likely working in conjunction with other networks during heat stress, and is shown to induce expression of small heat shock proteins (sHsps) and Hsp101 in Arabidopsis leaves under non-stressed conditions (Koskukll-Doring et al., 2007, and all references contained therein). HsfA3 is implicated is a crosstalk network with drought stress, with transcription in fact being induced DREB2A, in a cascade resulting in the transcription of genes encoding protective Hsps (Schramm et al., 2008, Yoshida et al., 2008, Chen et al., 2010).

The Hsp/Hsf network in plants response to heat stress is quite complex, and still being fully elucidated. Heat responses in monocots may increase the complexity of the network yet again. In contrast to tomato and Arabidopsis containing only one HsfA2, rice has five HsfA2 genes (von Koskull-Döring et al., 2007). Expression profiles of 12 class A OsHsfAs suggest different regulatory networks between heat and non-heat stress (Liu et al., 2009). A population of Arabidopsis was transformed with a full-length rice cDNA library in order to isolate the rice genes responsible for high-temperature stress tolerance (Yokotani et al., 2008),. A thermotolerant line encoding the rice the heat stress transcription factor OsHsfA2 fell out of the analysis as highly expressing several classes of heat-shock proteins (Yokotani et al., 2008), and also displaying tolerance to high-salinity stress. A genome-wide analysis of rice, including Oryza sativa L. ssp japonica and Oryza sativa L. ssp indica (Wang et al., 2009), identified 25 rice Hsf genes. Promoter analysis identified a number of stress-related ciselements in the promoter regions, however no correlation was found between heat-shock gene responses and their cis-elements. This study sets the foundation for future research into OsHsf function and tolerance. A recent study in the dicot grape (Vitis vinifera) identified four genes strongly upregulated by heat stress, whose overexpression resulted in the acquisition of thermotolerance in Arabidopsis (Kobayashi et al., 2010). Further in vivo studies in grape are underway to elucidate chaperone mechanisms, localization, and functions under stress conditions (Wang et al., 2009).

The complete mechanisms of Hsp mediated thermotolerance remains to be fully elucidated in plants; however work with transgenics has shown that altered levels of Hsps and Hsfs have dramatic effects on plants resistance to elevated temperatures. This offers a promising outlook for future research, utilizing non-model organisms and trials under realistic field conditions. Indeed, based on transcriptional response profiling, Arabidopsis Hsf and Hsp expression has been shown to be strongly induced by heat, cold, salt, (stresses sharing osmotic components), and upon wounding, suggesting an interaction point between multiple stress response pathways, warranting functional analysis under conditions apart from heat shock treatments, presenting another area for future research (Swindell et al., 2007).

\subsection{Drought}

A water deficit, along with freezing and increased $\mathrm{Na}+$ concentration, all disturb the water content of the cell, thus altering membrane fluidity, protein stability, and water potential gradients. This osmotic stress leads to wilting associated with loss of turgor pressure, and 
ultimately complete desiccation. Cellular sensors initially perceive and respond to the drought induced signaling, triggering gene expression changes to synthesize additional signals such as ABA. Further signaling cascades are then initiated to signal new gene expression patterns that are proposed to play a role in cellular adaptation to water-deficit stress (Bray 2002). Drought stress shares many of the same response pathways as the other osmotic stress pathways profiled earlier on the sections on salt and cold.

As with these other osmotic stressors, there are two classes of proteins synthesized as a result of cellular perception of drought stress. First the regulatory proteins; kinases, components of signaling transduction and amplification pathways such as ABA, and the transcription factors activating genes encoding protective proteins. The second class of proteins in the functional proteins, those serving protecting and chaperoning roles such as LEA proteins, osmoprotectants such as proline, proteins regulating water channels for turgor pressure, and proteases. It is these classes of proteins that have been the focus of genetic engineering for drought tolerance, as well as the focus of the following section.

A plethora of recent reviews exist on the physiological responses of the plant to drought stress (Yordanov et al., 2000, Wang et al., 2003, Bartels et al., 2005, Umezawa et al., 2006, Barnabas et al., 2008), and methods to engineer tolerance to water deficit. Readers interested in detailed background on drought stress are encouraged to read these reviews; this section offers only a small summary of some of the most recent discoveries and genetic engineering. Dehydrins are members of the LEA family of proteins and as mentioned previously aid in stabilizing proteins and other molecules during stresses, likely by replacing water to maintain homeostasis. Other hypotheses for roles played by LEA proteins are: compensating for the increasing ionic concentration by binding ions in dehydrated cells, and interaction with carbohydrates to prevent cellular damage during dehydration (Bartels 2005). Dehydrins are also present in fungi as well as plants; in the white truffle (Tuber borchii), a novel dehydrin-like coding gene displays increases transcript abundance during cellular dehydration (Abba et al., 2006). A promoter region from a dehydrin in coffee (Coffea canephora) has been cloned and implicated in osmotic stress-specific gene expression (Hinniger et al., 2005), and will be useful for studying control of gene expression during osmotic stress in coffee, an important crop.

Xerophytes are plants that are adapted to life in a low water environment, typically by employing altered root function. Watermelon (Citrullus lanatus) is one of these plants, and a recent study (Yoshimura et al., 2008) provides insights into the molecular mechanisms behind their adapted root system. In the early stages of drought stress watermelon displays enhanced root development, a drought avoidance mechanism for absorbing water deeper beneath the surface layer of soil. Proteome analysis revealed proteins induced in the early stage of drought stress to be involved in root morphogenesis and carbon/nitrogen metabolism, likely promoting rapid root development and growth. In later stages of drought stress however, the protein ratios shifted to lignin synthesis-related proteins and molecular chaperones, enhancing desiccation tolerance and protein stability. Developed root systems are not the only method plants use to survive in arid environments. Succulent xenophytes also show a greater abundance of free proline, up to 16 times greater than plants native to non-arid environments, as well as larger accumulations of $\mathrm{Na}^{+}$rather than $\mathrm{K}^{+}$for osmotic adjustment (Wang et al., 2004), perhaps acting as an effective strategy for their adaptation to arid environments. The tonoplast $\mathrm{Na}^{+} / \mathrm{H}^{+}$antiporter (NHX) is involved in the compartmentalization of cytosolic $\mathrm{Na}^{+}$into vacuoles. Zygophyllum xanthoxylum is a succulent xerophyte with a recently characterized ZxNHX antiporter demonstrated to be most active 
in the leaves. The transcript abundance of $Z x N H X$ under salt stress up to 8.4 times greater than unstressed plants and up to 4.4 times greater under drought conditions than unstressed controls (Wu et al., 2011), and may prove useful for future studies with crop species to predispose tolerance to both $\mathrm{Na}+$ and drought.

Desiccation tolerance is an adaptation to extreme environmental conditions, perhaps leading to abundant expression of hydrophilic proteins as a survival mechanism, such as the "resurrection plant", Craterostigma plantagineu (Bartels 2005). C. plantagineum has limited genomic information available, yet it is becoming evident (and not surprisingly) that desiccation tolerance is a complex trait, and probably linked to the recognition of cisregulatory sequences (Bartels 2005). However, it has been possible, based on homology inferences, to define four broad categories of C. plantagineum genes induced by dehydration: protective proteins including such as hydrophilins, regulatory proteins and RNA, carbohydrate metabolism enzymes, and proteins involved in water transport (Bartels 2005).

Other insights have come from naturally occurring desiccation tolerant plants, recently a 31$\mathrm{kDa}$ putative dehydrin polypeptide was discovered in the desiccation-tolerant fern Polypodium polypodioide, found to be localized at the cell walls and present only during drying (Layton et al. 2010). The protein rapidly dissipated upon tissue rehydration, along with changing the hydrophilicity of leaf surfaces and enabling reversible cell wall deformation. This suggests this protein potentially plays a role in avoiding mechanical failure during drought, and another angle to pursue with genetic engineering.

Transcriptome analysis of sub-lethal drought stress conditions in Arabidopsis identified three distinct stages of plant responses: initially an early "priming and preconditioning" stage, with early accumulation of ABA and associated signaling genes, which with a decrease in stomatal conductance, an intermediate stage preparatory for acclimation, and a late stage of new homeostasis with reduced growth. This is accompanied by a peak in expression of genes involved in cell wall expansion, likely as a preparatory step toward drought acclimation by the adjustment of the cell wall (Harb et al., 2010).

A recent microarray investigating genes responsible for drought tolerance between genotypes of barley; two drought-insensitive and one drought-sensitive, identified 17 genes that may play a role in enhancing tolerance (Guo et al., 2009). These genes are likely constitutively expressed in the two drought-insensitive genotypes, with their encoded proteins playing a role in their tolerance. These genes include those controlling stomatal closure via carbon metabolism (NADP malic enzyme, NADP-ME), those synthesizing the osmoprotectant glycine-betaine, those generating protectants against ROS scavenging, and those stabilizing membranes and proteins. Also found were genes enhancing $\mathrm{Ca}+$ signaling and molecular chaperoning. These findings allow a basis for selecting single genes conferring drought tolerance on cereals by transgenic means, and engineering for drought avoidance has taken advantage of the mechanisms for stomatal closure. For example, expression of the NADP-ME gene from maize has resulted in altered stomatal behavior and water relations when introduced into tobacco. The majority of water lost from plants occurs through stomata. When stomata are open, ions accumulate in order to increase the turgor pressure of the guard cells, which results in increased pore size (Laporte et al., 2002). Guard cells are present in pairs on the underside of leaves and surround the stomatal pores. These control both the $\mathrm{CO}_{2}$ influx required for photosynthesis and the loss of water to the atmosphere due to transpiration. Drought induced ABA synthesis signals stomatal closing, thus reducing stomatal aperture and ultimately reducing water loss (Schroeder et al., 2001). The transgenic NADP-ME tobacco displayed reduced stomatal conductance, yet 
importantly remained similar to the wild type in their growth and rate of development (Laporte et al., 2002).

MAPK cascades are implicated various signaling pathways involved in plant development and stress responses. A tobacco MAPKKK (NPK1) was constitutively expressed in maize, improving drought tolerance by maintaining higher photosynthesis rates than WT without affecting yield, producing a kernel yield comparable to well-watered WT plants (Shou et al., 2004). A novel MAPKKK gene, DSM1, has recently been characterized in rice, which functions as an early signaling component in regulating responses to drought stress by regulating scavenging of ROS (Ning et al., 2010). Overexpression of DSM1 in rice increases resistance to dehydration stress at the seedling stage.

In a study exposing nodulated alfalfa plants to drought conditions, it was shown much of the loss of alfalfa performance was due to reduced photosynthesis (in the leaves) and nitrogenase activity (in the nodules). Proteomic profiling showed a marked increase in proline levels, likely as a result of the intracellular increase in ROS (Aranjuelo et al., 2010). High levels of the osmoprotectant proline also resulted from the introduction of AtDREB1A/CBF3, driven by the inducible rd29A promoter, into tall fescue (Festuca arundinacea) (Zhao et al., 2007), which displayed increased resistance to drought.

The NAC family of plant-specific transcription factors plays roles in plant organ development, division, and resistance to pathogen attack (Hu et al., 2006) and all references therin). Some members of the NAC family are stress responsive, for example SNAC1 (STRESS-RESPONSIVE NAC 1) in induced in guard cells by drought stress, and when overexpressed in rice confers enhanced drought and salt resistance, without phenotypic changes or yield penalty under field conditions (Hu et al., 2006). Another novel rice NAC gene, ONAC045, is induced by drought, salt, cold, and ABA treatment (Zheng et al., 2009). ONAC045 was shown to function as a transcriptional activator, and rice plants overexpressing ONAC045 displayed enhanced tolerance to both drought and salt. Of the 140 OsNAC genes predicted in rice, 18 have been identified as being induced by stress conditions (Jeong et al., 2010). Of these, a recent functional genomics approach identified a rice NAC-domain gene, OsNAC10, which when under the control root-specific promoter (rather that the constitutive promoter GOS2) RCc3 displayed improved the drought tolerance and yield of transgenic rice plants grown under field drought conditions (Jeong et al., 2010). This represents another example of how spatial or temporal expressions of transgenes affect the growth habit and yield of the plant. Future research would benefit from utilizing promoters other that those offering constitutive expression when creating transgenics to both resist stress and maintain reproduction and yield.

As introduced in the salt section, promising results have been demonstrated by overexpressing vacuolar membrane $\mathrm{H}^{+}$pumps (Gaxiola et al., 2001, Park et al., 2005), allowing for an increase in vacuolar solute content, allowing for enhanced osmotic adjustment capacity. Recently AtAVP1 was introduced into cotton (Pasapula et al., 2010), with the transgenic phenotype displaying an increased vacuolar proton gradient, resulting in solute accumulation and water retention. The AVP1-expressing cotton plants also displayed a $20 \%$ increase in fiber yield when grown under field conditions. These results suggest a promising role for AVP1 in both drought and salt tolerance, perhaps offering the ability to reclaim farmland in arid regions (Pasapula et al., 2010).

The C4 grass foxtail millet (Setaria italica) not only harbors novel genes for increased salt tolerance (Puranik et al., 2011), but is also resistant to dehydration stress. Comparative transcriptome analysis under early and late drought stress identified the major upregulated 
transcripts to be involved in metabolism, signaling, transcriptional regulation, and proteolysis (Lata et al., 2010). Five cultivars of varying drought sensitivity were also screened for their dehydration tolerance, with differentially expressed transcripts identified between them. Selected examples of upregulated transcripts include: DREB2 (with a 5 fold increase after 6 hours. and an 11-fold increase after 24 hours), Ca+ dependent kinases (likely due to enhanced $\mathrm{Ca}+$ signaling), a member of the aquaporin superfamily, and the osmoprotectant thionin. Also shown to be upregulated in the more drought tolerant cultivars was the U2-snRNP, one of the 5 small ribonucleoprotein particles that make up the spliceosome, the regulator of both constitutive and alternative splicing in eukaryotes. This suggests an altered network of alternative splicing and gene regulation in foxtail millet under drought stress, offering an avenue for future research to pursue the gene targets and transcripts that undergo alternative splicing.

\subsection{Combinations of abiotic stressors: Profiles of heat and drought}

The combined physiological and molecular effects of heat and drought stress are quite complex, and it remains extremely difficult, if not impossible, to deduce these effects from observing the responses from one stress alone. For example, high leaf temperatures are a result of the combined effect because plants lose the ability for transpirational cooling when water availability is limited. When faced with high temperatures, plants will open their stomata in an effort to cool, however when drought is also introduced plants reduce their stomatal aperature in an effort to reduce water loss, which in turn increases temperatures within the leaf. This increase greatly perturbs cellular homeostasis and the activities of enzymes, membranes, and cellular homeostasis. A recent study in the perennial grass Leymus chinensis indicates high temperatures, combined with drought stress, reduces the function of PSII, weakens nitrogen anabolism, increases protein degradation, and provokes the peroxidation of lipids ( $\mathrm{Xu}$ and $\mathrm{Zhou,} \mathrm{2006).}$

The knowledge of the molecular effects of this combination in cereals remains rather limited, however a recent review (Barnabus et al., 2008) offers insights into the current physiological knowledge, and readers are directed to this detailed overview for more information. From initial development, to fertilization, to the development of reproductive organs and successful seed set, high light and drought stress put severe pressures on cereals. Of agricultural importance is the combination of these stresses on grain filling, the final stage of growth in cereals where fertilized ovaries develop into caryopses. This process is dependent on the remobilization of carbon from vegetative tissues to developing grain. Water stress during the grain-filling period induces early senescence, reduced photosynthesis, and shortens the grain-filling period; it increases the remobilization of nonstructural carbohydrates from the vegetative tissues to the grain (for a review see Yang et al., 2005). Under a combination of drought and heat stress, the amount of starch accumulation is greatly reduced, along with the activity of the enzymes responsible for starch synthesis, reducing grain weight. Around $65 \%$ of the dry weight of cereals can be accounted for by starch (Barnabus et al., 2008). ADP-glucose pyrophosphorylase (AGPase) is considered the rate limiting step in starch synthesis, and differs in thermostability between plants, for example the AGPases of cereal endosperms are heat labile, while those in potato (Solanum tuberosum) tubers, are heat stable (Linebarger et al., 2005). Recent research identified an N-terminal motif unique to heat-stable AGPases, and when inserted into corn (Zea mays) was shown to increase heat stability more than 300 -fold. This thermostability 
stems from a cysteine residue within the motif, giving rise to small subunit homodimers not found in the wild-type maize enzyme (Linebarger et al., 2005).

Trancriptome analysis is shedding light on the extent of the crosstalk network that exists between these abiotic stresses, which often result in the transcription of both overlapping and unique gene sets. This is not surprising given that a) several abiotic stresses share an osmotic (water loss) component and b) outside of a laboratory setting plants are exposed to combinations of stresses simultaneously, such as drought/heat or salt/drought, with the combined effects initiating unique transcriptome responses. Arabidopsis plants subjected to drought and heat stress display partial overlap of the two stress defense pathways individually, as well as 454 transcripts found to be specifically expressed during a combination of drought and heat stress (Rizhsky et al., 2004). These transcripts are characterized by enhanced respiration, suppressed photosynthesis, a complex expression pattern of defense and metabolic transcripts, and the accumulation of sucrose and other sugars. Interestingly heat stress was found to ameliorate the toxicity of proline to cells, suggesting that during a combination of drought and heat stress sucrose replaces proline in plants as the major osmoprotectant (Rizhsky et al., 2004). Microarray analysis of transgenic overexpressing DREB2A discovered upregulation of known drought and salt responsive genes but also heat shock related genes (Sakuma et al., 2006), implicating its function in an ABA independent regulon (Nakashima and Yamaguchi-Shinozaki et al., 2005).

Significant research is required to tease apart the molecular basis for this additive effect, yet given the current state of the field and the advent of high-throughput sequencing technologies combined with molecular cloning and characterization, the future remains bright for engineering plants with one or more additive genes conferring tolerance to heat and drought stress.

\section{High light}

Increases in light intensity over and above that which a plant can utilize in photosynthetic reactions is considered high light stress, and is extremely detrimental to the plant. This is in part due to accumulation of ROS, as well as the severely detrimental effects on photosynthesis and carbon fixation, all of which lead to cellular perturbations and ultimately result in crop loss or yield reduction. This high light induced photoinhibition causes reductions in the photosystem II (PSII) complex, and reduced photosynthetic $\mathrm{CO}_{2}$ fixation (Krause et al., 2005). The light driven PSII is found in the thylakoid membrane of chloroplasts, and also cyanobacteria, with the D1 and D2 protein complexes at its core. These sub-units act as the reaction center, binding chlorophyll, phenophytin, and plastoquinine co-factors involved in transmembrane induced charge separation (Nixon et al., 2010), with the redox state of the plastoquinine pool affecting signaling and chlorophyll fluorescence (Hohmann-Marriott et al., 2010). High light also synthesizes chloroplast antioxidant enzymes, with plastoquinol shown to be the main lipid-soluble antioxidant synthesized in Arabidopsis during the acclimation process (Szymańska et al., 2009).

Arabidopsis leaves respond to high light conditions by a gradual loss of chlorophyll; decreases to $79 \%, 78 \%$, and $66 \%$ of the initial value after 24,48 , and $72 \mathrm{~h}$ of high light acclimation, respectively, have been observed (Zelisko et al., 2005). The 2010 review by Nixon et al., summarizes the past 30 years of research into the assembly and repair of PSII, and readers are directed to this manuscript in depth discussion and mechanisms. The D1 and D2 proteins are subject to photodamage under high light. In mature chloroplasts, 
expression of the genes encoding D1 and D2 are transcriptionally upregulated in response to light, maintaining high rates of synthesis of the reaction centers, and therefore PSII activity under high intensity light conditions (Onda et al., 2008 and references therein).

The light harvesting complex (LHC II) of PSII is located in the thylakoid membrane of the chloroplast, collecting energy from sunlight and transferring it to the PSII reaction centers (Zelisko et al., 2005), and although the main function of LHC II is energy collection and transfer, it also is involved in the distribution of excitation energy between PS II and PS I. LHC II also plays a role in preventing damage to photosynthetic machinery when there is an excess of light, necessary for high light acclimatization. Recent work into elucidating the regulatory network in of proteases responsible discovered a chloroplast-targeted protease, AtFtsH6, identified as being responsible for the degradation of LHC II in Arabidopsis, with an ortholog in Populus trichocarpa. It is likely that FtsH6 is a general LHC II protease and that FtsH6-dependent LHC II proteolysis is a feature of all higher plants (Zelisko et al., 2005), and may play a role in the high light acclimatization process.

Leaf anatomy changes during photosynthetic light acclimation, for example leaves under shade display a reduction in the mesophyll cell palisade layer, allowing a wider area for light harvesting tissues, while chloroplasts under sunlight display more active carbon fixation carriers (such as Rubisco) and reaction centers (Weston et al., 2000), with lower amounts of thylakoids per chloroplast area. Arabidopsis leaves have been shown to develop elongated palisade mesophyll cells and increase leaf thickness under exposure to increased fluence rates (Weston et al., 2000). In addition to their role as photosynthetic centers, the chloroplasts also produce fatty acids and amino acids that act as secondary messengers and the building blocks of protein synthesis (López-Juez 2007).

Microarray studies have offered insights into global gene expression changes in response to high light stress in Arabidopsis. Enzymes of the phenylpropanoid pathway, specifically those involved in lignin and anthocyanin synthesis, were shown to accumulate under long exposures to high light (Kimura et al., 2003), perhaps as acting cellular protection mechanisms. Upregulation of stress-specific sigma factors (the Sig family) are evident as well. AtSig5 (AiSigE) is upregulated in response to light stress, suggesting a regulatory role in chloroplast gene expression under high light, and has also been shown to be induced under blue-light $(470 \mathrm{~nm}$ ) illumination (Onda et al., 2008). AtSIG5 likely protects plants from stresses by assisting and increasing repair of the PSII reaction center (Nagashima et al., 2004), as well as play a crucial role in plant reproduction (Yao et al., 2003). There appears to be at least some homology between dicot and monocot systems; recently the nuclear genes OsSIG5 and OsSIG6 were identified and demonstrated to encode chloroplast localized sigma factors in rice, as the first example of Sig5 in crop plants (Kubota et al., 2007).

Interestingly, but not entirely surprising, was the fact the array demonstrated high light stress induces genes associated with other abiotic stresses such as LEA14, COR15a, KIN1, and RD29a, as well as fibrillins (suggesting a role for the lipid protein plastoglobulin in chloroplast protection) and lipid transfer proteins. This is not surprising given the amounts of crosstalk in the abiotic stresses, as these genes are responsible for the encoding of proteins involved in protection of chaperoning, membrane protection, and other cellular components. The transcription factor DREB2A again fell out as overlapping with drought and high light specifically, likely induced by increasing ROS levels in chloroplasts under high light conditions (Kimura et al., 2003). One of the genes demonstrated to be upregulated more than 3-fold by Kimura et al., was a member of the early light-inducible protein (ELIP) family, ELIP2. Photoinhibition by high light also induces ELIP transcription in thylakoid 
membranes, corresponding to the degree of photoinhibition (Adamska et al., 1992), with chloroplast ELIP levels paralleling the decrease in the amount of D1 protein subunit of PSII. The expression pattern of ELIPs suggests a role in protection of the photosynthetic apparatus against photooxidative damage. Since Arabidopsis carries two ELIP genes (ELIP1/2), a double null mutant was created, of which the sensibility to photoinhibition and ability to recover from light stress was not different from WT (Rossini et al., 2006), raising questions about the photoprotective function of these proteins. Constitutive expression of AtELIP2 in Arabidopsis leaves decreased chloroplast chlorophyll content and caused a decrease in all photosynthetic pigments, however did not alter the composition, organization, or functionality of the photosystems. This indicates ELIPs are likely not directly involved in the synthesis and assembly of specific photosynthetic complexes, but rather affect the biogenesis of all chlorophyll-binding complexes (Tzvetkova-Chevolleau et al., 2007). Continued study will be necessary to fully elucidate the photoprotective role of the ELIP family, perhaps suggesting they may not be the best candidates for genetic engineering to increase high light tolerance.

There has been little research using genetic engineering to increase the photosynthetic capability of agriculturally important crop species, yet given the insights we have gained from global transcriptome studies, and traditional genetic approaches have characterized genes enhancing cellular protection, altering photosynthesis, and involved with various aspects of high light acclimatization. The coming years now have the benefit of a wealth of genomic information, and identification of factors participating in signaling between the nucleus and chloroplast; allowing for directed studies into increased photochemical quenching, dissipation of excess light energy, and reduction of ROS.

\section{Future of abiotic stress research: Incorporating the genomics revolution}

The next decade of research into abiotic stress tolerance promises to be both an exiting and fruitful one. It has the advantage of an existing bank of knowledge in the form of public gene expression data from microarray and HTS experiments, new emerging monocot model systems closely related to the cereals, and the coupling of traditional breeding with genetic engineering. New insights into the gene regulatory networks regulating stress-relevant pathways are continuing to emerge, and natural variation between cultivars or accessions, when coupled with high-throughput sequencing and quantitative phenotyping for improved stress tolerance, can pinpoint candidate genes for future study.

Since the advent of genome-wide surveys of expression patterns and differential regulation under various conditions, huge datasets of stress-specific genes have begun to amass. These datasets are incorporated into public databases, and freely searchable by the research community. Now that we have begun to identify subsets of genes and gene families induced under stresses, it is time to utilize this knowledge towards high-throughput screens of transgenic plants expressing genes under stress induced or tissue specific promoters. It is through such large scale functional genomic approaches that genes or gene combinations will be identified that are capable of conferring tolerance to the abiotic stress of interest without detrimental effects to reproduction or yield. To date most such transgenic studies have relied most often on a candidate gene first identified in the dicot Arabidopsis, fused to a constitutive promoter, and grown under laboratory conditions for a short duration. While often resulting in a plant demonstrating improved stress tolerance, such studies are of limited value unless conducted in a crop species and under realistic field conditions, and can be likened to chipping 
away at an iceberg. Given the genome scale datasets available now it is plausible to directly identify novel genes or groups of genes in a crop itself or a closely related model system suited for laboratory study. Two relevant and recently emerging models are the grasses Brachypodium and Setaria. Brachypodium is member of the Pooideae subfamily of grasses and a well suited model system due to its relatively small fully sequenced and annotated genome, growing mutant collection, transcriptome sequence data, and other genetic resources (The International Brachypodium Initiative et al., 2010). Setaria is a C4 grass (Brutnell et al., 2010), as are corn, sugarcane, and sorghum, and therefore lends itself as a model for these agriculturally important crops. C4 plants have the ability to withstand higher light intensities and temperatures than C3 plants (wheat, barley, etc.) and information derived from Setaria may allow for improved viability of other crop species in new geographic regions.

One crucial issue that has only been touch upon briefly in this chapter, due to space constraints, is traditional breeding for increased stress tolerance. Abiotic stress tolerance is a complex trait, and it remains difficult to breed for tolerance without effecting yield or viability. There are many previous reviews (Bruce et al., 2001, Price et al., 2002, Withcombe et al., 2008, Ashraf et al., 2010) focusing on QTL and breeding cereals for stress tolerance, as well as genetic engineering coupled with breeding; and readers are directed to these reviews for further information. Future efforts will likely combine breeding and genetic engineering to maximize the benefits to both tolerance and yield. For example, a QTL involved in stress tolerance may bring undesirable closely linked traits, which may in turn be compensated by with complementary transgenes. The technology for such approaches is available now, and the challenge will be translating the laboratory discoveries into field studies and vice versa.

Research into improving stress tolerance has historically focused primarily on transcription factors. Transcription factors are master regulators of the response network, directly controlling either a single gene of multiple gene products. In addition, post-transcriptional regulation is mediated by splicing factors, specifically, by members the SR family of splicing factors, that are themselves alternatively spliced under abiotic stresses (Palusa et al., 2007, Filichkin et al., 2010). This layer of regulation of gene expression likely alters the splicing of a host of downstream genes in response to abiotic stresses, including transcription factors, and may simultaneously target multiple response mechanisms. Future research towards understanding the regulatory web of transcription factors, splicing factors, and their targets will be necessary in order to elucidate the foundations of abiotic stress tolerance in plants.

The next decade of abiotic stress research in plants has the potential to take great strides towards fully understanding stress response gene networks and translating this combined knowledge into increased crop yields. The knowledge gained from high-throughput and genome-scale technologies, coupled with the work of breeders, may allow us to meet the world's ever increasing demand for food, despite our growing population.

\section{References}

Abba, S., Ghignone, S., Bonfante, P. (2006). A dehydration-inducible gene in the truffle Tuber borchii identifies a novel group of dehydrins. BMC Genomics, Vol.7, No.39, (March 2006), ISSN 1471-2164

Abraham, E., Rigo, G., Szekely, G., Nagy, R., Koncz, C., Szabados, L. (2003). Lightdependent induction of proline biosynthesis by abscisic acid and salt stress is 
inhibited by brassinosteroid in Arabidopsis. Plant Molecular Biology, Vol.51, No.3, (Febuary 2003), pp. 363-372, ISSN 1677-0420

Adamska, I. (1997). ELIPs - Light-induced stress proteins. Physiologia Plantarum ,Vol.100, No.4, (August 1997), pp. 794-805, ISSN 0031-9317

Agarwal, M., Hao, Y., Kapoor, A., Dong, C.-H., Fujii, H., Zheng, X., et al. (2006). A R2R3 Type MYB Transcription Factor Is Involved in the Cold Regulation of CBF Genes and in Acquired Freezing Tolerance. Journal of Biological Chemistry ,Vol. 281, No.49, (October 2006), pp. 37636-37645, ISSN 0021-9258

Apse, M. P., Aharon, G. S., Snedden, W. A., Blumwald, E. (1999). Salt Tolerance Conferred by Overexpression of a Vacuolar Na+/H+ Antiport in Arabidopsis. Science,Vol.285, No.5431, (August 1999), pp. 1256-1258, ISSN 0028-0836

Aranjuelo, I., Molero, G., Erice, G., Avice, J. C., Noques, S. (2010). Plant physiology and proteomics reveals the leaf response to drought in alfalfa (Medicago sativa L.). Journal of Experimental Botany, Vol.62, No.1, (August 2010), pp.1-13, ISSN 0022-0957

Ashraf, M. (2010). Inducing drought tolerance in plants: Recent advances. Biotechnology Advances, No. 28,Vol.1, (January 2010), pp. 169-183, ISSN 0734-9750

Badawi, M., Reddy, Y. V., Agharbaoui, Z., Tominaga, Y., Danyluk, J., Sarhan, F., Houde, M. (2008) Structure and functional analysis of wheat ICE (Inducer of CBF Expression) genes. Plant and Cell Physiology, Vol.48, No.9, (July 2008), pp. 1237-1249, ISSN 00320781

Baniwal, S., Bharti, K., Chan, K., Fauth, M., Ganguli, A., Kotak, S., Mishra, S., Nover, L., Port, M., Scharf, K.-D., Tripp, J., Weber, C., Zielinski, D., von Koskull-Doring, P. (2004). Heat stress response in plants, a complex game with chaperones and more than twenty heat stress transcription factors. Journal of Biosciences, Vol.29, No.4, (December 2004), pp. 471-487, ISSN 0250-5991

Banti, V., Mafessoni, F., Loreti, E., Alpi, A., Perata, P. (2010). The Heat-Inducible Transcription Factor HsfA2 Enhances Anoxia Tolerance in Arabidopsis. C, Vol.152, No.3, (March 2010), pp. 1471-1483, ISSN 0032-0889

Barnabás, B., Jäger, K., Fehér, A. (2008). The effect of drought and heat stress on reproductive processes in cereals. Plant cell environment, Vol.31, No.1, (January 2008), pp. 11-38, ISSN 0140-7791

Bartels, D. (2005). Desiccation Tolerance Studied in the Resurrection Plant Craterostigma plantagineum. Integrative and Comparative Biology, Vol.45, No.5, (December 2001), pp. 696-701, ISSN 1540-7063

Biamonti, G. and Caceres, J. F. (2009). Cellular stress and RNA splicing. Trends in Biochemical Sciences, Vol.34, No.3, (March 2009), pp.146-153, ISSN 0968-0004

Bohnert, H., J., Nelson, D. E. \& Jensen, R. G. (1995) Adaptations to Environmental Stresses. The Plant Cell Online, Vol.7, No.7, (July 1005), pp. 1099-1111, ISSN 1040-4651

Bray, E. A. (2002). Abscisic acid regulation of gene expression during water-deficit stress in the era of the Arabidopsis genome. Plant, Cell Environment, Vol.25, No.2, (Febuary 2002), pp. 153-161, ISSN 0140-7791

Brinker, M., Brosch, M., Vinocur, B., Abo-Ogiala, A., Fayyaz, P., Janz, D. (2010). Linking the Salt Transcriptome with Physiological Responses of a Salt-Resistant Populus Species as a Strategy to Identify Genes Important for Stress Acclimation. Plant Physiology, Vol.154, No.4, (December 2010), pp. 1697-1709, ISSN 0032-0889 
Bruce, W. B., Edmeades, G. O., Barker, T. C. (2002). Molecular and physiological approaches to maize improvement for drought tolerance. Journal of Experimental Botany, Vol.53, No.366, (Jamuary 2002), pp. 13-25, ISSN 0022-0957

Brutnell, T. P., Wang, L., Swartwood, K., Goldschmidt, A., Jackson, D., Zhu, X.-G., Kellogg, E. \& Van Eck, J. (2010). Setaria viridis, A Model for C4 Photosynthesis.The Plant Cell Online, Vo.22, No.8, (August 2010), pp. 2537-2544, ISSN 1532-298X

Carden, D. E., Walker, D. J., Flowers, T. J., Miller, A. J. (2003). Single-Cell Measurements of the Contributions of Cytosolic $\mathrm{Na}+$ and $\mathrm{K}+$ to Salt Tolerance. Plant Physiology, Vol.131, No.2, (Febuary 2003), pp. 676-683, ISSN 0032-0889

Chaikam, V., Karlson, D. (2008). Functional characterization of two cold shock domain proteins from Oryza sativa. Plant, Cell Environment,Vol.31, No.7, (July 2008), pp. 995-1006, ISSN 0140-7791

Charng, Y.,Liu, H., Liu, N., Chi, W., Wang, C., Chang, S.(2007). A Heat-Inducible Transcription Factor, HsfA2, Is Required for Extension of Acquired Thermotolerance in Arabidopsis. Plant Physiology,Vol.143, No.1, (January 2007), pp. 251-262, ISSN 0032-0889

Chaves, M. M., Flexas, J., Pinheiro, C. (2009). Photosynthesis under drought and salt stress: regulation mechanisms from whole plant to cell. Annals of Botany, Vol.103, No.4, (Febuary 2009), pp. 551-560, ISSN 0305-7364

Chen, H., Hwang, J. E., Lim, C. J., Kim, D. Y., Lee, S. Y., Lim, C. O. (2010). Arabidopsis DREB2C functions as a transcriptional activator of HsfA3 during the heat stress response. Biochemical and Biophysical Research Communications,Vol. 401, No.2, (October 2010), pp.238-244, ISSN 1090-2104

Chen, W., J., Zhu, T. (2004). Networks of transcription factors with roles in environmental stress response. Trends in Plant Science, Vol.9, no.12, (December 2004), pp. 591-596, ISSN 1360-1385

Chinnusamy, V., Zhu, J., Zhu, J.-K. (2007). Cold stress regulation of gene expression in plants. Trends in Plant Science, Vol. 12, No.10, (October 2007), pp. 444-451, ISSN 1360-1385

Cohen-Peer, R., Schuster, S., Meiri, D., Breiman, A., Avni, A. (2010). Sumoylation of Arabidopsis heat shock factor A2 (HsfA2) modifies its activity during acquired thermotholerance. Plant Molecular Biology, Vol.74, No.1-2, (September 2010), pp. 3345, ISSN 0167-4412

Craterostigma plantagineum. Integrative and Comparative Biology, Vol.45, No.5, (November 2005), pp. 696-701, ISSN 1540-7063

Cuevas, J. C., Lopez-Cobollo, R., Alcazar, R., Zarza, X., Koncz, C., Altabella, T., Salinas, J., Tiburcio, A. F., Ferrando, A. (2008). Putrescine is involved in Arabidopsis freezing tolerance and cold acclimation by regulating ABA levels in response to low temperature. Plant Physiology, Vol.148, No.2, (October 2008), pp. 1094-1105, ISSN 0032-0889

Doherty, C. J., Van, H. A., Myers, S. J., Thomashow, M. F. (2009). Roles for Arabidopsis CAMTA Transcription Factors in Cold-Regulated Gene Expression and Freezing Tolerance. The Plant Cell, Vol.21, No.3, (March 2009), pp. 972-984, ISSN 1040-4651

Dong, C., Danyluk, J., Wilson, K. E., Pocock, T., Huner, N. P., Sarhan, F. (2002). ColdRegulated Cereal Chloroplast Late Embryogenesis Abundant-Like Proteins. 
Molecular Characterization and Functional Analyses. Plant Physiology, Vol.129, No.3, (July 2002), pp.1368-1381, ISSN 0032-0889

Dong, C.-H., Agarwal, M., Zhang, Y., Xie, Q., Zhu, J.-K. (2006). The negative regulator of plant cold responses, HOS1, is a RING E3 ligase that mediates the ubiquitination and degradation of ICE1. Proceedings of the National Academy of Sciences, Vol.103, No.21, (May 2006), pp. 8281-8286, ISSN 0027-8424

Egawa, C., Kobayashi, F., Ishibashi, M., Nakamura, T., Nakamura, C., Takumi, S. (2006). Differential regulation of transcript accumulation and alternative splicing of a DREB2 homolog under abiotic stress conditions in common wheat. Genes Genetic Systems, Vol.81, No.2, (April 2006), pp. 77-91. ISSN 1341-7568

Feder, M. E., Hofmann, G. E. (1999). Heat-shock proteins, molecular chaperones, and the stress response: evolutionary and ecological physiology. Annual Review of Physiology, Vol.61, No.1, (March 1999), pp. 243-282, ISSN 0066-4278

Filichkin, S. A., Priest, H. D., Givan, S. A., Shen, R., Bryant, D. W., Fox, S. E., Wong, W. K., Mockler, T. C. (2009). Genome-wide mapping of alternative splicing in Arabidopsis thaliana. Genome Research, Vol.20, No.1, (January 2010), pp. 45-58, ISSN 1088-9051

Flowers, T., Garcia, A., Koyama, M. \& Yeo, A. (1997) Breeding for salt tolerance in crop plants - the role of molecular biology Acta Physiologiae Plantarum, Vol.10, No.4, (1997), pp. 427-433, ISSN 1861-1664

Forment, J., Naranjo, M. Á., Roldán, M., Serrano, R., Vicente, O. (2002). Expression of Arabidopsis SR-like splicing proteins confers salt tolerance to yeast and transgenic plants. The Plant Journal, Vol.30, No.5, (June 2002), pp. 511-519, ISSN 0960-7412

Fourrier, N., Bédard, J., Lopez-Juez, E., Barbrook, A., Bowyer, J., Jarvis, P., Warren, G., Thorlby, G. (2008) A role for SENSITIVE TO FREEZING2 in protecting chloroplasts against freeze-induced damage in Arabidopsis. The Plant Journal, Vol.55, No.5, (September 2008), pp.734-745, ISSN 0960-7412

Fowler, S. G., Cook, D., Thomashow, M. F. (2005). Low Temperature Induction of Arabidopsis CBF1, 2, and 3 Is Gated by the Circadian Clock. Plant Physiology, Vol.137, No.3, (March 2005), pp. 961-968, ISSN 0032-0889

Franklin, K., Whitelam, G. (2007). Light-quality regulation of freezing tolerance in Arabidopsis thaliana. Nature Genetics, Vol.39, No.5, (November 2007), pp. 14101413, ISSN 1061-4036

Fukuda, A., Nakamura, A., Tagiri, A., Tanaka, H., Miyao, A., Hirochika, H., Tanaka, Y. (2004). Function, Intracellular Localization and the Importance in Salt Tolerance of a Vacuolar Na+/H+ Antiporter from Rice. Plant and Cell Physiology, Vol.45, No.2, (January 2004), pp. 146-159, ISSN 0032-0781

Fursova, O. V., Pogorelko, G. V., Tarasov, V. A. (2009). Identification of ICE2, a gene involved in cold acclimation which determines freezing tolerance in Arabidopsis thaliana. Gene, Vol.429, No.1-2, (January 2009), pp. 98-103, ISSN 0378-1119

Garciadeblás, B., Haro, R., Benito, B. (2007). Cloning of two SOS1 transporters from the seagrass Cymodocea nodosa, SOS1 transporters from Cymodocea and Arabidopsismediate potassium uptake in bacteria. Plant Molecular Biology, Vol.63, No.4, (March 2007), pp. 479-490, ISSN 0167-4412

Gaxiola, R. A., Li, J., Undurraga, S., Dang, L. M., Allen, G. J., Alper, S. L., Fink, G. R. (2001). Drought- and salt-tolerant plants result from overexpression of the AVP1 H+- 
pump. Proceedings of the National Academy of Sciences, Vol.98, No.20, (September 2001), pp. 11444-11449, ISSN 0027-8424

Ghoulam, C., Foursy, A., Fares, K. (2002). Effects of salt stress on growth, inorganic ions and proline accumulation in relation to osmotic adjustment in five sugar beet cultivars. Environmental and Experimental Botany, Vol.47, No.1, (January 2002), pp. 39-50, ISSN 0098-8472

Gilmour, S. J., Zarka, D. G., Stockinger, E. J., Salazar, M. P., Houghton, J. M., Thomashow, M. F. (1998). Low temperature regulation of the Arabidopsis CBF family of AP2 transcriptional activators as an early step in cold-induced COR gene expression. The Plant Journal, Vol.16. No.4, (November 1998), pp. 433-442, ISSN 1365-313X

Gray, W. M., Ostin, A., Sandberg, G., Romano, C. P., Estelle, M. (1998). High temperature promotes auxin-mediated hypocotyl elongation in Arabidopsis. Proceedings of the National Academy of Sciences, Vol.95, No.12, (June 1998), pp. 7197-7202, ISSN 00278424

Guo, P., Baum, M., Grando, S., Ceccarelli, S., Bai, G., Li, R. (2009). Differentially expressed genes between drought-tolerant and drought-sensitive barley genotypes in response to drought stress during the reproductive stage. Journal of Experimental Botany, Vol.60, No.12, (June 2009) , pp. 3531-3544, ISSN 0022-0957

Guo, Y.-Q., Tian, Z.-Y., Qin, G.-Y., Yan, D.-L., Zhang, J., Zhou, W.-Z, Qin, P. (2009). Gene expression of halophyte Kosteletzkya virginica seedlings under salt stress at early stage. Genetica, Vol.137, No.2, (November 2009), pp. 189-199, ISSN 0016-6707

Haake, V., Cook, D., Riechmann, J., Pineda, O., Thomashow, M. F., Zhang, J. Z. (2002). Transcription Factor CBF4 Is a Regulator of Drought Adaptation in Arabidopsis. Plant Physiology, Vol.130, No.2, (October 2002), pp. 639-648, ISSN 0032-0889

Halfter, U., Ishitani, M., Zhu, J.-K. (2000). The Arabidopsis SOS2 protein kinase physically interacts with and is activated by the calcium-binding protein SOS3. Proceedings of the National Academy of Sciences, Vol.97, No.1, (March 2000), pp. 3735-3740, ISSN 0027-8424

Harb, A., Krishnan, A., Ambavaram, M. M., Pereira, A. (2010). Molecular and Physiological Analysis of Drought Stress in Arabidopsis Reveals Early Responses Leading to Acclimation in Plant Growth. Plant Physiology, Vol.154, No.3, (August 2010), pp.1254-1271, ISSN 0032-0889

Hare, P., Cress, W. \& van Staden, J. (1999). Proline synthesis and degradation, a model system for elucidating stress-related signal transduction. Journal of Experimental Botany, Vol.50, No.333, (January 1999), pp.413-434, ISSN 0022-0957

Hinniger, C., Caillet, V., Michoux, F., BenAmor, M., Tanksley, S., Lin, C., Mccarthy, J. (2006). Isolation and Characterization of cDNA Encoding Three Dehydrins Expressed During Coffea canephora (Robusta) Grain Development. Annals of Botany, Vol.97, No.5, (May 2006), pp. 755-765, ISSN 0305-7364

Hohmann-Marriott, M. F., Takizawa, K., Eaton-Rye, J. J., Mets, L., Minagawa, J. (2010). The redox state of the plastoquinone pool directly modulates minimum chlorophyll fluorescence yield in Chlamydomonas reinhardtii. FEBS Letters, Vol.584, No.5, (March 2010), pp. 1021-1026, ISSN 0014-5793

Hu, H., Dai, M., Yao, J., Xiao, B., Li, X., Zhang, Q., Xiong, L. (2006). Overexpressing a NAM, ATAF, and CUC (NAC) transcription factor enhances drought resistance and salt 
tolerance in rice. Proceedings of the National Academy of Sciences, Vol.103, No.35, (June 2006), pp. 12987-12992, ISSN 0027-8424

Hu, H., You, J., Fang, Y., Zhu, X., Qi, Z., Xiong, L. (2008). Characterization of transcription factor gene SNAC2 conferring cold and salt tolerance in rice. Plant Molecular Biology,Vol.67, No.102, (May 2008), pp. 169-181, ISSN 0167-4412

Huang, J., Hirji, R., Adam, L., Rozwadowski, K. L., Hammerlindl, J. K., Keller, W. A., Selvaraj, G. (2000). Genetic Engineering of Glycinebetaine Production toward Enhancing Stress Tolerance in Plants: Metabolic Limitations. Plant Physiology, Vol.122, No.3, (March 2000), pp. 747-756, ISSN 0032-0889

Hundertmark, M., Hincha, D. (2008). LEA proteins and their encoding genes in Arabidopsis thaliana. BMC Genomics, Vol.9, No.1, (March 2008), pp. 118, ISSN 1471-2164

Iida, K., Seki, M., Sakurai, T., Satou, M., Akiyama, K., Toyoda, T., Konagaya, A., Shinozaki, K. (2004). Genome-wide analysis of alternative pre-mRNA splicing in Arabidopsis thaliana based on full-length cDNA sequences. Nucleic Acids Research,Vol. 32, No.17, (September 2004), pp. 5096-5103, ISSN 0305-1048

International Brachypodium Initiative. (2010). Genome sequencing and analysis of the model grass Brachypodium distachyon. Nature, Vol.463, No.7282, (February 2010), pp. 763-768, ISSN 0028-0836

Ishitani, M., Liu, J., Halfter, U., Kim, C., Shi, W., Zhu, J. (2000). SOS3 function in plant salt tolerance requires N-myristoylation and calcium binding. Plant Cell, Vol.12, No.9, (September 2000), pp. 1667-78, ISSN 1040-4651

Ishitani, M., Xiong, L., Stevenson, B., Zhu, J. K. (1997). Genetic Analysis of Osmotic and Cold Stress Signal Transduction in Arabidopsis: Interactions and Convergence of Abscisic Acid-Dependent and Abscisic Acid-Independent Pathways. The Plant Cell Online , 9 (11), 1935-1949.

Jaspers, P., \& Kangasjärvi, J. (2010) Reactive oxygen species in abiotic stress signaling. Physiologia Plantarum, Vol.138, No.4, (April 2010), pp. 405-413, ISSN 1399-3054

Jeong, J. S., Kim, Y. S., Baek, K. H., Jung, H., Ha, S.-H., Choi, Y. D., et al. (2010). Root-Specific Expression of OsNAC10 Improves Drought Tolerance and Grain Yield in Rice under Field Drought Conditions. Plant Physiology, Vol.153, No.1, (May 2010), pp. 185-197, ISSN 0032-0889

Johnson-Flanagan, A. M., Huiwen, Z., Thiagarajah, M. R., Saini, H. S. (1991). Role of Abscisic Acid in the Induction of Freezing Tolerance in Brassica napus SuspensionCultured Cells. Plant Physiology, Vol.95, No.4, (April 1991), pp. 1044-1048, ISSN 0032-0889

Jones-Rhoades, M. W., Bartel, D. P., Bartel, B. (2006). MicroRNAs and their regulatory roles in plants. Annual Review of Plant Biology, Vol.57, (June 2006) pp. 19-53, ISSN 15435008

Kanaoka, M. M., Pillitteri, L. J., Fujii, H., Yoshida, Y., Bogenschutz, N. L., Takabayashi, J., Zhu, J.-K., Torii, K. U. (2008). SCREAM/ICE1 and SCREAM2 Specify Three CellState Transitional Steps Leading to Arabidopsis Stomatal Differentiation. The Plant Cell, Vol.20, No.7, (July 2008), pp.1775-1785, ISSN 1040-4651

Katiyar-Agarwal, S., Agarwal, M., Grover, A. (2003). Heat-tolerant basmati rice engineered by over-expression of hsp101. Plant Molecular Biology, Vol.51, No.5, (March 2003), pp. 677-686, ISSN 0167-4412 
Katiyar-Agarwal, S., Zhu, J., Kim, K., Agarwal, M., Fu, X., Huang, A., Zhu, J. (2006). The plasma membrane $\mathrm{Na}+\mathrm{H}+$ antiporter SOS1 interacts with RCD1 and functions in oxidative stress tolerance in Arabidopsis. Proceedings of the National Academy of Sciences, Vol. 103, No.49, (December 2006) pp. 18816-18821, ISSN 0027-8424

Kern, A., J., and Dyer, W. E. (2004). Glycine Betaine Biosynthesis Is Induced by Salt Stress but Repressed by Auxinic Herbicides in Kochia scoparia. Journal of Plant Growth Regulation, Vol.23, No.1, (March 2004), pp. 9-19, ISSN 0721-7595

Kidokoro, S., Maruyama, K., Nakashima, K., Imura, Y., Narusaka, Y., Shinwari, Z. K., Osakabe, Y., Fujita, Y., Mizoi, J., Shinozaki, K., Yamaguchi-Shinozaki, K. (2009). The Phytochrome-Interacting Factor PIF7 Negatively Regulates DREB1 Expression under Circadian Control in Arabidopsis. Plant Physiology, Vol.151, No.4, (December 2009), pp.2046-2057, ISSN 0032-0889

Kim, D.-Y., Jin, J.-Y., Alejandro, S., Martinoia, E., Lee, Y. (2010). Overexpression of AtABCG36 improves drought and salt stress resistance in Arabidopsis. Physiologia Plantarum, Vol.139, No.2, (June 2010), pp. 170-180, ISSN 0031-9317

Kim, J. S., Park, S. J., Kwak, K. J., Kim, Y. O., Kim, J. Y., Song, J., Boseung Jang, B., Jung, C., Kang, H. (2006). Cold shock domain proteins and glycine-rich RNA-binding proteins from Arabidopsis thaliana can promote the cold adaptation process in Escherichia coli. Nucleic Acids Research, Vol.35, No.2, (December 2006), pp. 506-516, ISSN 0305-1048

Kim, K., Portis, A. R. (2005). Temperature Dependence of Photosynthesis in Arabidopsis Plants with Modifications in Rubisco Activase and Membrane Fluidity. Plant and Cell Physiology, Vol.46, No.3, (Febuary 2005), pp. 522-530, ISSN 0032-0781

Kimura, M., Yamamoto, Y. Y., Seki, M., Sakurai, T., Sato, M., Abe, T., Yoshida, S., Manabe, K., Shinozaki, K., Matsui, M. (2003). Identification of Arabidopsis Genes Regulated by High Light-Stress Using cDNA Microarray. Photochemistry and Photobiology, Vol.77, No.2, (February 2003), pp.226-233, ISSN 0031-8655

Kishitani, S., Watanabe, K., Yasuada, S., Arakawa, K., Takabe, T. (1994). Accumulation of glycinebetaine during cold acclimation and freezing tolerance in leaves of winter and spring barley plants. Plant, Cell E Environment, Vol.17, No.1, (January 1994), pp. 89-95, ISSN 0140-7791

Knight, H., Zarka, D. G., Okamoto, H., Thomashow, M. F., Knight, M. R. (2004) Abscisic Acid Induces CBF Gene Transcription and Subsequent Induction of ColdRegulated Genes via the CRT Promoter Element. Plant Physiology, Vol.135, No.3, (July 2004), pp. 1710-1717, ISSN 0032-0889

Knox, A., Dhillon, T., Cheng, H., Tondelli, A., Pecchioni, N., Stockinger, E. (2010). CBF gene copy number variation at Frost Resistance-2 is associated with levels of freezing tolerance in temperate-climate cereals. Theoretical and Applied Genetics, Vol.121, No.1, (June 2010), pp. 21-35, ISSN 0040-5752

Komatsu, S., Yang, G., Khan, M., Onodera, H., Toki, S., Yamaguchi, M. (2007). Overexpression of calcium-dependent protein kinase 13 and calreticulin interacting protein 1 confers cold tolerance on rice plants. Molecular Genetics and Genomics, Vol.277, No.6, (June 2007), pp. 713-723, ISSN 1617-4615

Kotak, S., Vierling, E., Bäumlein, H., von Koskull-Döring, P. (2007). A Novel Transcriptional Cascade Regulating Expression of Heat Stress Proteins during Seed Development 
of Arabidopsis. The Plant Cell, Vol.19, No.1, (January 2007), pp. 182-195, ISSN 10404651

Kovacs, D., Agoston, B., Tompa, P. (2008).Disordered plant LEA proteins as molecular chaperones. Plant Signal Behavior, Vol.3, No.9, (September 2008), pp.710-713, ISSN 1559-2316

Krause, G. H., Gallé, A., Virgo, A., García, M., Bucic, P., Jahns, P., Winter, K. (2006). HighLight Stress does not Impair Biomass Accumulation of Sun-Acclimated Tropical Tree Seedlings (Calophyllum longifolium Willd. and Tectona grandis L. f.). Plant Biology, Vol.8, No.1, (January 2006), pp. 31-41, ISSN 1435-8603

Kreps, J. A., Wu, Y., Chang, H.-S., Zhu, T., Wang, X. \& Harper, J. F. (2002) Transcriptome Changes for Arabidopsis in Response to Salt, Osmotic, and Cold Stress. Plant Physiology, Vol.130, No.4, (December 2002), pp. 2129-2141, ISSN 15322548

Kubota, Y., Miyao, A., Hirochika, H., Tozawa, Y., Yasuda, H., Tsunoyama, Y., Niwa, Y., Imamura, S., Shirai, M., Asayama, M. (2007). Two Novel Nuclear Genes, OsSIG5 and OsSIG6, Encoding Potential Plastid Sigma Factors of RNA Polymerase in Rice: Tissue-Specific and Light-Responsive Gene Expression. Plant and Cell Physiology, Vol.48, No.1, (January 2007), pp. 186-192, ISSN 1471-9053

Kurek, I., Chang, T. K., Bertain, S. M., Madrigal, A., Liu, L., Lassner, M. W., Zhu, G. (2007). Enhanced Thermostability of Arabidopsis Rubisco Activase Improves Photosynthesis and Growth Rates under Moderate Heat Stress. The Plant Cell, Vol.19, No.10, (October 2007), pp. 3230-3241, ISSN 1040-4651

Laporte, M. M., Shen, B., Tarczynski, M. C. (2002). Engineering for drought avoidance: expression of maize NADP malic enzyme in tobacco results in altered stomatal function. Journal of Experimental Botany, Vol.53, No.369, (April 2002), pp. 699-705, ISSN 1460-2431

Lata, C., Sahu, P. P., Prasad, M. (2010). Comparative transcriptome analysis of differentially expressed genes in foxtail millet (Setaria italica L.) during dehydration stress. Biochemical and Biophysical Research Communications, Vol.393, No.4, (March 2010), pp. 720-727, ISSN 1090-2104

Layton, B. E., Boyd, M. B., Tripepi, M. S., Bitonti, B. M., Dollahon, M. N. R., Balsamo, R. A. (2010). Dehydration-induced expression of a 31-kDa dehydrin in Polypodium polypodioides (Polypodiaceae) may enable large, reversible deformation of cell walls. American Journal of Botany, Vol.97, No.4, (March 2010), pp. 535-544, ISSN 0002-9122

Lee, B., Kapoor, A., Zhu, J., Zhu, J.-K. (2006). STABILIZED1, a Stress-Upregulated Nuclear Protein, Is Required for Pre-mRNA Splicing, mRNA Turnover, and Stress Tolerance in Arabidopsis. The Plant Cell, Vol.18, No.7, (July 2006), pp. 1736-1749, ISSN 1040-4651

Lee, B.-h., Lee, H., Xiong, L., Zhu, J.-K. (2002). A Mitochondrial Complex I Defect Impairs Cold-Regulated Nuclear Gene Expression. The Plant Cell, Vol.14, No.6, (June 2002), pp. 1235-1251. ISSN 1040-4651

Li, C., Chen, Q., Gao, X., Qi, B., Chen, N., Xu, S., Chen, J., Wang, X. (2005). AtHsfA2 modulates expression of stress responsive genes and enhances tolerance to heat and oxidative stress in Arabidopsis. Science in China Series C: Life Sciences, Vol.46, No.8, (December 2005), pp.540-550, ISSN 1006-9305 
Li, M., Berendzen, K., Schöffl, F. (2010). Promoter specificity and interactions between early and late Arabidopsis heat shock factors. Plant Molecular Biology, Vol.73, No.4-5 (July 2010), pp. 559-567, ISSN 0167-4412

Li, P., Brutnell, T. P. (2011). Setaria viridis and Setaria italica, model genetic systems for the Panicoid grasses. Journal of Experimental Botany, Epub ahead of print, (May 2011), ISSN 0022-0957

Li, T., Zhang, Y., Liu, H., Wu, Y., Li, W., Zhang, H. (2010). Stable expression of Arabidopsis vacuolar $\mathrm{Na}^{+} / \mathrm{H}^{+}$antiporter gene AtNHX1 and salt tolerance in transgenic soybean for over six generations. Chinese Science Bulletin,Vol. 55, No.12, (April 2010), pp. 1127-1134, ISSN 1001-6538

Li, W., Wang, D., Jin, T., Chang, Q., Yin, D., Xu, S., Liu, B.,Liu, L. (2010). The Vacuolar $\mathrm{Na}+\mathrm{H}+$ Antiporter Gene SsNHX1 from the Halophyte Salsola soda Confers Salt Tolerance in Transgenic Alfalfa (Medicago sativa L.). Plant Molecular Biology Reporter, Vol.29, No.2, (July 2010), pp. 278-290, ISSN 1572-9818

Linebarger, C. R. L., Boehlein, S. K., Sewell, A. K., Shaw, J., Hannah, L. C. (2005). Heat Stability of Maize Endosperm ADP-Glucose Pyrophosphorylase Is Enhanced by Insertion of a Cysteine in the N Terminus of the Small Subunit. Plant Physiology, Vol.139, No.4, (December 2005), pp. 625-1634, ISSN 0032-0889

Liu, A.-L., Zou, J., Zhang, X.-W., Zhou, X.-Y., Wang, W.-F., Xiong, X.-Y., Chen, L.-Y., Chen, X.-B. (2010). Expression Profiles of Class A Rice Heat Shock Transcription Factor Genes Under Abiotic Stresses. Journal of Plant Biology, Vol.53, No.2, (January 2010), pp. 142-149, ISSN 1226-9239

Liu, J., Zhu, J.-K. (1998). A Calcium Sensor Homolog Required for Plant Salt Tolerance. Science, Vol.280, No.5371, (June 1998), pp. 1943-1945, ISSN 0036-8075

Liu, Q., Kasuga, M., Sakuma, Y., Abe, H., Miura, S., Yamaguchi-Shinozaki, K., Shinozaki, K. (1998). Two Transcription Factors, DREB1 and DREB2, with an EREBP/AP2 DNA Binding Domain Separate Two Cellular Signal Transduction Pathways in Droughtand Low-Temperature-Responsive Gene Expression, Respectively, in Arabidopsis. The Plant Cell, Vol. 10, No.8, (August 1998), pp. 1391-1406, ISSN 1040-4651

Liu, X., Yang, J., Li, B., Yang, X., Meng, Q. (2010) Antisense expression of tomato chloroplast omega-3 fatty acid desaturase gene (LeFAD7) enhances the tomato hightemperature tolerance through reductions of trienoic fatty acids and alterations of physiological parameters. Photosynthetica, Vol.48, No.1, (January 2010) pp. 59-66, ISSN 0300-3604

Liu, Y., Xiong, Y., Bassham, D. C. (2009). Autophagy is required for tolerance of drought and salt stress in plants. Autophagy,Vol. 5, No.7, (October 2009), pp. 954-963, ISSN 1554-8627

Llorente, F., Oliveros, J. C., Martínez-Zapater, J. M., Salinas, J. (2000). A freezing-sensitive mutant of Arabidopsis frs1 is a new aba3 allele. Planta, Vol.211, No.5, (October 2000), pp. 648-655, ISSN 0032-0935

Lopez-Juez, E. (2007). Plastid biogenesis, between light and shadows. Journal of Experimental Botany, Vol.58, No.1, (January 2007), pp. 11-26, ISSN 0022-0957

Ma, S., Gong, Q., Bohnert, H. J. (2006). Dissecting salt stress pathways. Journal of Experimental Botany, Vol.57, No.5, (March 2006), pp. 1097-1107, ISSN 0022-0957 
Mahajan, S., Tuteja, N. (2005). Cold, salinity and drought stresses: An overview. Archives of Biochemistry and Biophysics, Vol.444, No.2, (December 2005), pp. 139-158, ISSN 00039861

Martanez, J.-P., Lutts, S., Schanck, A., Bajji, M., Kinet, J.-M. (2004). Is osmotic adjustment required for water stress resistance in the Mediterranean shrub Atriplex halimus L? Journal of Plant Physiology, Vol.161, No.9, (September 2004), pp. 1041-1051, ISSN 0032-0889

Martínez-Atienza, J., Jiang, X., Garciadeblas, B., Mendoza, I., Zhu, J.-K., Pardo, J., M., Quintero, F., J. (2007). Conservation of the Salt Overly Sensitive Pathway in Rice. Plant Physiology, Vol.143, No.2, (February 2007), pp. 1001-1012, ISSN 0032-0889

Matsui, A., Ishida, J., Morosawa, T., Mochizuki, Y., Kaminuma, E., Endo, T. A., Okamoto., M., Nambara., E., Nakajima., M., Kawashima., M., Satou., M., Kim., J., Kobayashi., N., Toyoda., T., Shinozaki., K., Seki., M. (2008). Arabidopsis Transcriptome Analysis under Drought, Cold, High-Salinity and ABA Treatment Conditions using a Tiling Array. Plant and Cell Physiology, Vol.49, No.8, (July 2008), pp. 1135-1149, ISSN 0032-0781

Maughan, P.,J., Turner, T.,B., Coleman, C.,E., Elzinga, D.,B., Jellen, E.,N., Morales JA, Udall JA, Fairbanks DJ, Bonifacio A. (2009). Characterization of Salt Overly Sensitive 1 (SOS1) gene homoeologs in quinoa (Chenopodium quinoa Willd.). Genome, Vol.52, No.7, (July 2009), pp. 647-657, ISSN 0831-2796

Miller, G., Shulaev, V., Mittler, R. (2008). Reactive oxygen signaling and abiotic stress. Physiologia Plantarum, Vol.133, No.33, (July 2008), pp. 481-489, ISSN 0031-9317

Mishra, S. K., Tripp, J., Winkelhaus, S., Tschiersch, B., Theres, K., Nover, L., Scharf, K.-D. (2002). In the complex family of heat stress transcription factors, HsfA1 has a unique role as master regulator of thermotolerance in tomato. Genes $\mathcal{E}$ Development, Vol.16, No.12, (May 2002), pp. 1555-1567, ISSN 0890-9369

Mittler, R., Kim, Y., Song, L., Coutu, J., Coutu, A., Ciftci-Yilmaz, S., Lee, H., Stevenson, B., Zhu, J. (2006). Gain- and loss-of-function mutations in Zat10 enhance the tolerance of plants to abiotic stress. FEBS Letters, Vol.580, No.28-29, (December 2006), pp. 6537-6542, ISSN 0014-5793

Miura, K., Jin, J. B., Lee, J., Yoo, C. Y., Stirm, V., Miura, T., et al. (2007). SIZ1-Mediated Sumoylation of ICE1 Controls CBF3/DREB1A Expression and Freezing Tolerance in Arabidopsis. The Plant Cell, Vol.19, No.4, (April 2007), pp. 1403-1414, ISSN 10404651

Mizuno, H., Kawahara, Y., Sakai, H., Kanamori, H., Wakimoto, H., Yamagata, H., Oono, Y., Wu, J., Ikawa, H., Itoh, T., Matsumoto, T. (2010). Massive parallel sequencing of mRNA in identification of unannotated salinity stress-inducible transcripts in rice (Oryza sativa L.). BMC Genomics, Vol.11, No.1, (December 2010), pp. 683, ISSN 1471-2164

Moellering, E. R., Muthan, B., Benning, C. (2010). Freezing Tolerance in Plants Requires Lipid Remodeling at the Outer Chloroplast Membrane. Science, Vol.330, No.6001, (October 2010), pp. 226-228, ISSN 0036-8075

Mohanty, S. and Tripathy, B. (2010). Early and late plastid development in response to chill stress and heat stress in wheat seedlings. Protoplasma, Epub ahead of print, (November 2010), pp.1-12, ISSN 1615-6102 
Monroy, A. F., Dhindsa, R. S. (1995). Low-Temperature Signal Transduction: Induction of Cold Acclimation-Specific Genes of Alfalfa by Calcium at 25C. The Plant Cell, Vol.7, No.3, (March 1995), pp. 321-331, ISSN 1040-4651

Munns, R. (2002). Comparative physiology of salt and water stress. Plant, Cell $\mathcal{E}$ Environment, Vol. 25, No.2, (February 2002), pp. 239-250, ISSN 0140-7791

Nagashima, A., Hanaoka, M., Shikanai, T., Fujiwara, M., Kanamaru, K., Takahashi, H., Tanaka, K. (2004). The Multiple-Stress Responsive Plastid Sigma Factor, SIG5, Directs Activation of the psbD Blue Light-Responsive Promoter (BLRP) in Arabidopsis thaliana. Plant and Cell Physiology, Vol.55, No.4, (April 2004), pp. 357368, ISSN 0032-0781

Nakaminami, K., Karlson, D. T., Imai, R. (2006). Functional conservation of cold shock domains in bacteria and higher plants. Proceedings of the National Academy of Sciences, Vol.103, No.26, (June 2006), pp. 10122-10127, ISSN 0027-8424

Nakashima, K., and Yamaguchi-Shinozaki, K. (2005). Molecular Studies on StressResponsive Gene Expression in Arabidopsis and Improvement of Stress Tolerance in Crop Plants by Regulon Biotechnology. Physiologia Plantarum, Vol.126, No.1, (January 2006), pp. 62-71, ISSN 0021-3551

Nakayama, K., Okawa, K., Kakizaki, T., Inaba, T.(2008). Evaluation of the Protective Activities of a Late Embryogenesis Abundant (LEA) Related Protein, Cor15am, during Various Stresses in Vitro. Bioscience, Biotechnology, and Biochemistry, Vol.72, No.6, (June 2006), pp. 1642-1645, ISSN 0916-8451

Ning, J., Li, X., Hicks, L. M., Xiong, L. A. (2010) Raf-Like MAPKKK Gene DSM1 Mediates Drought Resistance through Reactive Oxygen Species Scavenging in Rice. Plant Physiology, Vol.152, No.2, (February 2010), pp. 876-890, ISSN 0032-0889

Nixon, P. J., Michoux, F., Yu, J., Boehm, M., Komenda, J. (2010) Recent advances in understanding the assembly and repair of photosystem II. Annals of Botany, Vol.106, No.1, (March 2010), pp. 1-16, ISSN 0305-7364

Nover, L., Bharti, K., Döring, P., Mishra, S., K., Ganguli, A., Scharf, K-D. (2001). Arabidopsis and the heat stress transcription factor world: how many heat stress transcription factors do we need? Cell Stress Chaperones, Vol.6, No.3, (April 2001), pp.177.189, ISSN 1355-8145

Novillo, F., Alonso, J. M., Ecker, J. R., Salinas, J. (2004). CBF2/DREB1C is a negative regulator of CBF1/DREB1B and CBF3/DREB1A expression and plays a central role in stress tolerance in Arabidopsis. Proceedings of the National Academy of Sciences of the United States of America, Vol.101, No.11, (March 2004), pp. 3985-3990, ISSN 00278424

Novitskaya, G., V., Suvorova, T. A., Trunova, T. I. (2000). Lipid Composition of Tomato Leaves as Related to Plant Cold Tolerance. Russian Journal of Plant Physiology, Vol. 47, No.6, (January 2000), pp. 728-733, ISSN 1021-4437

Oh, S.-J., Song, S. I., Kim, Y. S., Jang, H.-J., Kim, S. Y., Kim, M., et al. (2005). Arabidopsis CBF3/DREB1A and ABF3 in Transgenic Rice Increased Tolerance to Abiotic Stress without Stunting Growth. Plant Physiology, Vol.138, No.1, (May 2005), pp. 341-351, ISSN 0032-0889

Ohnishi, N. and Murata, N. (2006). Glycinebetaine Counteracts the Inhibitory Effects of Salt Stress on the Degradation and Synthesis of the D1 Protein during Photoinhibition 
in Synechococcus. Plant Physiology, Vol.141, No.2, (June 2006), pp. 758-765, ISSN 0032-0889

Olías, R., Eljakaoui, Z., Pardo, J. M., Belver, A. (2009). The Na+/H+ exchanger SOS1 controls extrusion and distribution of $\mathrm{Na}+$ in tomato plants under salinity conditions. Plant Signal Behavior, Vol.4, No.10, (October 2009),pp.973-976,ISSN1559-2316

Onda, Y., Yagi, Y., Saito, Y., Takenaka, N., Toyoshima, Y. (2008). Light induction of Arabidopsis SIG1 and SIG5 transcripts in mature leaves: differential roles of cryptochrome 1 and cryptochrome 2 and dual function of SIG5 in the recognition of plastid promoters. The Plant Journal, Vol.55, No.6, (September 2008), pp. 968-978. ISSN 0960-7412

Ottow, E. A., Brinker, M., Teichmann, T., Fritz, E., Kaiser, W., Brosché, M., Kangasjärvi, J., Jiang, X., Polle, A. (2005). Populus euphratica Displays Apoplastic Sodium Accumulation, Osmotic Adjustment by Decreases in Calcium and Soluble Carbohydrates, and Develops Leaf Succulence under Salt Stress. Plant Physiology, Vol.139, No.4, (November 2005), pp. 1762-1772, ISSN 0032-0889

Palusa, S. G., Ali, G. S., Reddy, A. S. (2007). Alternative splicing of pre-mRNAs of Arabidopsis serine/arginine-rich proteins: regulation by hormones and stresses. The Plant Journal, Vol.49, No.6, (March 2007), pp. 1091-1107, ISSN 0960-7412

Park, S. J., Kwak, K. J., Oh, T. R., Kim, Y. O., Kang, H. (2009). Cold Shock Domain Proteins Affect Seed Germination and Growth of Arabidopsis thaliana Under Abiotic Stress Conditions. Plant and Cell Physiology, Vol.50, No.4, (April 2009), pp.869-878, ISSN 0032-0781

Park, S., Li, J., Pittman, J. K., Berkowitz, G. A., Yang, H., Undurraga, S., et al. (2005). Upregulation of a $\mathrm{H}+$-pyrophosphatase (H+-PPase) as a strategy to engineer droughtresistant crop plants. Proceedings of the National Academy of Sciences of the United States of America, Vol.102, No.52, (December 2005), pp. 18830-18835, ISSN 0027-8424

Pasapula, V., Shen, G., Kuppu, S., Paez-Valencia, J., Mendoza, M., Hou, P., Chen, J., Qiu, X., Zhu, L., Zhang, X., Auld, D., Blumwald, E., Zhang, H., Gaxiola, R., Payton, P. (2011). Expression of an Arabidopsis vacuolar H+-pyrophosphatase gene (AVP1) in cotton improves drought- and salt tolerance and increases fibre yield in the field conditions. Plant Biotechnology Journal, Vol.9, No.1, (January 2011), pp. 88-99, ISSN 1467-7644

Pennycooke, J., Cheng, H., Roberts, S., Yang, Q., Rhee, S., Stockinger, E. (2008). The low temperature-responsive, Solanum CBF1 genes maintain high identity in their upstream regions in a genomic environment undergoing gene duplications, deletions, and rearrangements. Plant Molecular Biology, Vol.67, No.5, (July 2008), pp. 483-497, ISSN 0167-4412

Price, A. H., Cairns, J. E., Horton, P., Jones, H. G., Griffiths, H. (2002). Linking droughtresistance mechanisms to drought avoidance in upland rice using a QTL approach: progress and new opportunities to integrate stomatal and mesophyll responses. Journal of Experimental Botany, Vol.53, No.371, (January 2002), pp. 989-1004, ISSN 0022-0957

Qin, F., Sakuma, Y., Li, J., Liu, Q., Li, Y.-Q., Shinozaki, K., Yamaguchi-Shinozaki, K. (2004). Cloning and Functional Analysis of a Novel DREB1/CBF Transcription Factor Involved in Cold-Responsive Gene Expression in Zea mays L. Plant and Cell Physiology, Vol.45, No.8, (May 2004), pp. 1042-1052, ISSN 0032-0781 
Rabbani, M. A., Maruyama, K., Abe, H., Khan, M. A., Katsura, K., Ito, Y., Yoshiwara, K., Seki, M., Shinozaki, K., Yamaguchi-Shinozaki., K. (2003). Monitoring Expression Profiles of Rice Genes under Cold, Drought, and High-Salinity Stresses and Abscisic Acid Application Using cDNA Microarray and RNA Gel-Blot Analyses. Plant Physiology, Vol.133, No.4, (December 2003), pp. 1755-1767, ISSN 0032-0781

Reddy, A. S. (2007). Alternative Splicing of Pre-Messenger RNAs in Plants in the Genomic Era. Annual Review of Plant Biology, Vol.58, (June 2007), pp. 267-294, ISSN 1543-5008

Rekarte-Cowie, I., Ebshish, O. S., Mohamed, K. S., Pearce, R. S. (2008). Sucrose helps regulate cold acclimation of Arabidopsis thaliana. Journal of Experimental Botany, Vol.59, No.15, (November 2008), pp. 4205-4217, ISSN 0022-0957

Rensink, W., Hart, A, Liu, J., Ouyang, S., Zismann, V., Buel,l CR. (2005) Analyzing the potato abiotic stress transcriptome using expressed sequence tags. Genome, Vol.48,, No.4, (August 2005), pp. 598-605, ISSN 0225-7149

Rizhsky, L., Liang, H., Shuman, J., Shulaev, V., Davletova, S., Mittler, R. (2004). When Defense Pathways Collide. The Response of Arabidopsis to a Combination of Drought and Heat Stress. Plant Physiology, Vol.134, No.4, (April 2004), pp.16831696, ISSN 0032-0889

Rorat, T. (2006). Plant dehydrins - Tissue location, structure and function. Cellular $\mathcal{E}$ Molecular Biology Letters, Vol.11, No.4, (September 2006), pp. 536-556, ISSN 14258153

Rossini, S., Casazza, A. P., Engelmann, E. C., Havaux, M., Jennings, R. C., Soave, C. (2006). Suppression of Both ELIP1 and ELIP2 in Arabidopsis Does Not Affect Tolerance to Photoinhibition and Photooxidative Stress. Plant Physiology, Vol.141, No.4, (August 2006), pp. 1264-1273, ISSN 0032-0889

Saijo, Y., Hata, S., Kyozuka, J., Shimamoto, K., Izui, K. (2000). Over-expression of a single $\mathrm{Ca} 2+-$ dependent protein kinase confers both cold and salt/drought tolerance on rice plants. The Plant Journal, Vol.23, No.3, (August 2000), pp. 319-327, ISSN 09607412

Sakamoto, A., Murata, N. (2000). Genetic engineering of glycinebetaine synthesis in plants: current status and implications for enhancement of stress tolerance. Journal of Experimental Botany, Vol.51, No.342, (January 2000), pp. 81-88, ISSN 0022-0957

Sakuma, Y., Maruyama, K., Qin, F., Osakabe, Y., Shinozaki, K., Yamaguchi-Shinozaki, K. (2006). Dual function of an Arabidopsis transcription factor DREB2A in water and heat-stress-responsive gene expression. Proceedings of the National Academy of Sciences, Vol.103, No.49, (December 2006), pp. 18822-18827, ISSN

Salvucci, M. E., Osteryoung, K. W., Crafts-Brandner, S. J., Vierling, E. (2001). Exceptional Sensitivity of Rubisco Activase to Thermal Denaturation in vitro and In vivo. Plant Physiology, Vol.127, No.3, (November 2001), pp. 1053-1064, ISSN 0032-0781

Sasaki, K., Saito, T., Lämsä, M., Oksman-Caldentey, K.-M., Suzuki, M., Ohyama, K., Muranaka, T., Ohara, K., Yazaki, K. (2007). Plants Utilize Isoprene Emission as a Thermotolerance Mechanism. Plant and Cell Physiology, Vol.48. No.9, (August 2007), pp. 1254-1262, ISSN 00320781

Schramm, F., Larkindale, J., Kiehlmann, E., Ganguli, A., Englich, G., Vierling, E., Von Koskull-Döring, P. (2008). A cascade of transcription factor DREB2A and heat stress transcription factor HsfA3 regulates the heat stress response of Arabidopsis. The Plant Journal, Vol.53, No.2, (January 2008), pp. 264-274, ISSN 0960-7412 
Schroeder, J., Kwak, J., Allen, G. (2001). Guard cell abscisic acid signalling and engineering drought hardiness in plants. Nature, Vol.410, No.6826, (March 2001), pp. 327-30, ISSN 0028-0836

Serrano, R., Mulet, J. M., Rios, G., Marquez, J. A., F., I. i., Leube, M. P., Mendizabal, I., Pascual-Ahuir, A., Proft, M., Ros, R., Montesinos, C. (1999). A glimpse of the mechanisms of ion homeostasis during salt stress. Journal of Experimental Botany, Vol.50, No. Special Issue, (June 1999), pp. 1023-1036, ISSN 0022-0957

Shabala, S. and Cuin, T.A.(2008). Potassium transport and plant salt tolerance. Physiologia Plantarum, Vol.133,No.4,(August 2008), pp. 651-669, ISSN 0031-9317

Shi, H., Kim, Y., Guo, Y., Stevenson, B., Zhu, J.-K. (2002).The Arabidopsis SOS5 Locus Encodes a Putative Cell Surface Adhesion Protein and Is Required for Normal Cell Expansion. The Plant Cell Online, Vol.15, No.1, (January 2002), pp. 19-32, ISSN 1532$298 X$

Shibasaki, K., Uemura, M., Tsurumi, S. \& Rahman, A. (2009). Auxin Response in Arabidopsis under Cold Stress, Underlying Molecular Mechanisms. The Plant Cell, Vol.21, No.12, (December 2009), pp. 3823-3838, ISSN 1040-4651

Shinozaki, K., Yamaguchi-Shinozaki, K. (2000). Molecular responses to dehydration and low temperature: differences and cross-talk between two stress signaling pathways. Current Opinion in Plant Biology, Vol.3, No.3, (June 2000), pp. 217-223, ISSN

Shinozaki, K., Yamaguchi-Shinozaki, K. (2007). Gene networks involved in drought stress response and tolerance. Journal of Experimental Botany, Vol.58, No.2, (January 2007), pp. 221-227, ISSN 0022-0957

Shou, H., Bordallo, P., Wang, K. (2004). Expression of the Nicotiana protein kinase (NPK1) enhanced drought tolerance in transgenic maize. Journal of Experimental Botany, Vol.75, No.5, (May 2005), pp. 1013-1019, ISSN 0022-0957

Skinner, J., Szucs, P., Zitzewitz, J. v., Marquez-Cedillo, L., Filichkin, T., Stockinger, E., Thomashow, M., F., Chen, T., H., H., Hates, P., M.. (2006). Mapping of barley homologs to genes that regulate low temperature tolerance in Arabidopsis. TAG Theoretical and Applied Genetics, Vol.112, No.5, (January 2006), pp.832-842, ISSN 0040-5752

Sohn, S., Back, K. (2007). Transgenic rice tolerant to high temperature with elevated contents of dienoic fatty acids. Biologia Plantarum, Vol.51, No.2, (June 2007), pp. 340342, ISSN 0006-3134

Steponkus, P., L., Lynch, D., V. (1989). Freeze/thaw-induced destabilization of the plasma membrane and the effects of cold acclimation. Journal of Bioenergetics and Biomembranes, Vol.21, No.1, (February 1989), pp. 21-41, ISSN 0145-479X

Stockinger, E. J., Skinner, J. S., Gardner, K. G., Francia, E., Pecchioni, N. (2007) Expression levels of barley $\mathrm{Cbf}$ genes at the Frost resistance-H2 locus are dependent upon alleles at Fr-H1 and Fr-H2. The Plant Journal, Vol.51, No.12, (July 2007), pp.308-321, ISSN 0960-7412

Su, C.-F., Wang, Y.-C., Hsieh, T.-H., Lu, C.-A., Tseng, T.-H., Yu, S.-M. (2010). A Novel MYBS3-Dependent Pathway Confers Cold Tolerance in Rice. Plant Physiology, Vol.153, No.1, (May 2010), pp. 145-158, ISSN 0032-0889

Sung, S., Amasino, R. M. (2004). Vernalization and epigenetics: how plants remember winter. Current Opinion in Plant Biology, Vol.7, No.1, (Feb 2004), pp. 4-10, ISSN 1369-5266 
Sunkar, R., Zhu, J.-K. (2004). Novel and Stress-Regulated MicroRNAs and Other Small RNAs from Arabidopsis. The Plant Cell Online, Vol.16, No.8, (August 2004), pp. 2012019, ISSN 1040-4651

Sunkar, R., Chinnusamy, V., Zhu, J., Zhu, J.-K. (2007). Small RNAs as big players in plant abiotic stress responses and nutrient deprivation. Trends in Plant Science, Vol.12, No.7, (July 2007), pp. 301-309, ISSN 1360-1385

Sutton, F., Ding, X., Kenefick, D. G. (1992). Group 3 LEA Gene HVA1 Regulation by Cold Acclimation and Deacclimation in Two Barley Cultivars with Varying Freeze Resistance . Plant Physiology, Vol.99, No.1, (May 1992), pp. 338-340, ISSN 0032-0889

Swindell, W., Huebner, M., Weber, A. (2007). Transcriptional profiling of Arabidopsis heat shock proteins and transcription factors reveals extensive overlap between heat and non-heat stress response pathways. BMC Genomics,Vol.8, No.125 (March 2007), ISSN 1471-2164)

Szymanska, R. and Kruk, J. (2010). Plastoquinol is the Main Prenyllipid Synthesized During Acclimation to High Light Conditions in Arabidopsis and is Converted to Plastochromanol by Tocopherol Cyclase. Plant and Cell Physiology, Vol.51, No.4, (February 2010), pp. 537-545, ISSN 1471-9053

Takuhara, Y., Kobayashi, M., Suzuki, S. (2011) Low-temperature-induced transcription factors in grapevine enhance cold tolerance in transgenic Arabidopsis plants. Journal of Plant Physiology, Vol.168, No.9, (June 2011), pp. 967 - 975, ISSN 0176-1617

Tamura, K., Yamada, T. (2007). A perennial ryegrass CBF gene cluster is located in a region predicted by conserved synteny between Poaceae species. TAG Theoretical and Applied Genetics, Vol.114, No.2, (January 2007), pp. 273-283, ISSN 0040-5752

Tanabe, N., Yoshimura, K., Kimura, A., Yabuta, Y., Shigeoka, S. (2007). Differential Expression of Alternatively Spliced mRNAs of Arabidopsis SR Protein Homologs, atSR30 and atSR45a, in Response to Environmental Stress. Plant and Cell Physiology, Vol.48, No.7, (July 2007), pp. 1036-1049, ISSN 0032-0781

Tang, L., Kwon, S.-Y., Kim, S.-H., Kim, J.-S., Choi, J., Cho, K., Chang K. Sung, K., C., Kwak, S., Le, H. (2006). Enhanced tolerance of transgenic potato plants expressing both superoxide dismutase and ascorbate peroxidase in chloroplasts against oxidative stress and high temperature. Plant Cell Reports, Vol.25, No. 12, (July 2006), pp. 13801386 ISSN 0721-7714

Tester, M. and Davenport, R. (2003), Na+ Tolerance and Na+ Transport in Higher Plants. Annals of Botany, Vol.91, No.5, (April 2003), pp. 503-527, ISSN 0305-7364

Thomashow, M. (1999). Plant cold acclimation, Freezing tolerance genes and regulatory mechanisms. Annual Review of Plant Physiology and Plant Molecular Biology, Vol.50, (June 1999), pp. 571-599, ISSN 1040-2519

Thomashow, M. F. (1998). Role of Cold-Responsive Genes in Plant Freezing Tolerance. Plant Physiology, Vol.118, No.1, (September 1998), pp. 1-8, ISSN 0032-0889

Thomashow, M. F. (2001). So What's New in the Field of Plant Cold Acclimation? Lots! Plant Physiology, Vol.125, No.1, (January 2001), pp. 89-93, ISSN 0032-0889

Thomashow, M., F. (2010). Molecular basis of plant cold acclimation, insights gained from studying the CBF cold response pathway. Plant Physiology, Vol.154, No.2, (October 2010), pp. 571-577, ISSN 0032-0889

Thorlby, G., Fourrier, N., Warren, G. (2004). The SENSITIVE TO FREEZING2 Gene, Required for Freezing Tolerance in Arabidopsis thaliana, Encodes a beta- 
Glucosidase. The Plant Cell, Vol. 16, No.8, (August 2004), pp. 2192-2203, ISSN 10404651

Tian, Y., Zhang, H., Pan, X., Chen, X., Zhang, Z., Lu, X., Huang, R. (2010). Overexpression of ethylene response factor TERF2 confers cold tolerance in rice seedlings. Transgenic Research, Epub ahead of print, (December 2010), ISSN 0962-8819

Tzvetkova-Chevolleau, T., Franck, F., Alawady, A. E., Dall'Osto, L., Carrière, F., Bassi, R., Grimm, B., Nussaume, L., Havaux, M. (2007). The light stress-induced protein ELIP2 is a regulator of chlorophyll synthesis in Arabidopsis thaliana. The Plant Journal , Vol. 50, No.5, (June 2007), pp. 795-809, ISSN 0960-7412

Uemura, M., Joseph, R., A., Steponkus, P.,l. (1995) Cold Acclimation of Arabidopsis thaliana (Effect on Plasma Membrane Lipid Composition and Freeze-Induced Lesions). Plant Physiology, Vol.109, No.1, (September 1995), pp. 15-30, ISSN 0032-0889

Umezawa, T., Fujita, M., Fujita, Y., Yamaguchi-Shinozaki, K., Shinozaki, K. (2006). Engineering drought tolerance in plants: discovering and tailoring genes to unlock the future. Current Opinion in Biotechnology, Vol.17, No.2, (April 2006), pp. 113-122, ISSN 0958-1669

Vera-Estrella, R., Barkla, B. J., García-Ramírez, L. and Pantoja, O. (2005). Salt Stress in Thellungiella halophila Activates $\mathrm{Na}+$ Transport Mechanisms Required for Salinity Tolerance. Plant Physiology, Vol.139, No.3, (November 2005), pp. 1507-1517, ISSN 0032-0889

Villalobos, M. A., Bartels, D. \& Iturriaga, G. (2004). Stress Tolerance and Glucose Insensitive Phenotypes in Arabidopsis Overexpressing the CpMYB10 Transcription Factor Gene. Plant Physiology,Vol.135, No.1, (May 2004), pp. 309-324 , ISSN 1532-2548

Vogel, J. T., Zarka, D. G., Van, H. A., Fowler, S. G., Thomashow, M. F. (2005). Roles of the CBF2 and ZAT12 transcription factors in configuring the low temperature transcriptome of Arabidopsis. The Plant Journal, Vol.41, No.2, (January 2005), pp. 195-211, ISSN 0960-7412

von Koskull-Döring, P., Scharf, K.-D., Nover, L. (2007). The diversity of plant heat stress transcription factors. Trends in Plant Science, Vol.12, No.10, (October 2007), pp. 452 - 457, ISSN 1360-1385

Wahid, A., Gelani, S., Ashraf, M., Foolad, M. (2007). Heat tolerance in plants, An overview. Environmental and Experimental Botany, Vol.61, No.3, (December 2007), pp. 199 - 223, ISSN 0098-8472

Wang, C., Zhang, Q., Shou, H.-x. (2009). Identification and expression analysis of OsHsfs, in rice. Journal of Zhejiang University - Science B, Vol.10, No.4, (April 2009), pp. 291-300, ISSN 1673-1581

Wang, S., Wan, C., Wang, Y., Chen, H., Zhou, Z., Fu, H., Sosebee, R., E. (2004). The characteristics of $\mathrm{Na}+, \mathrm{K}+$ and free proline distribution in several drought-resistant plants of the Alxa Desert, China. Journal of Arid Environments, Vol.56 No.3, (Febuary 2004), pp. 525-539, ISSN 0140-1963

Wang, W., Vinocur, B., Altman, A. (2003). Plant responses to drought, salinity and extreme temperatures: towards genetic engineering for stress tolerance. Planta, Vol.218, No.1, (November 2003), pp. 1-14, ISSN 0032-0935

Wang, W., Vinocur, B., Shoseyov, O., Altman, A. (2004). Role of plant heat-shock proteins and molecular chaperones in the abiotic stress response. Trends in Plant Science,Vol. 9, No.5, (May 2004), pp. 244-252, ISSN 1360-1385 
Wang, W., Vinocur, B., Shoseyov, O., Altman, A. (2004). Role of plant heat-shock proteins and molecular chaperones in the abiotic stress response. Trends in Plant Science, Vol.9, No.5, (May 2004), pp. 244 - 252, ISSN 1360-1385

Wang, X., Li, W., Li, M., Welti, R. (2006). Profiling lipid changes in plant response to low temperatures. Physiologia Plantarum, Vol.126, No.1, (January 2006), pp. 90-96, ISSN 0031-9317

Watanabe, S., Kojima, K., Ide, Y., Sasaki, S. (2000). Effects of saline and osmotic stress on proline and sugar accumulation in Populus euphratica in vitro. Plant Cell, Tissue and Organ Culture, Vol.63, No. 3, (November 2000), pp. 199-206, ISSN 0167-6857

Webb, M. S., Uemura, M., Steponkus, P. L. (1994). A Comparison of Freezing Injury in Oat and Rye: Two Cereals at the Extremes of Freezing Tolerance. Plant Physiology, Vol.104, No.2, (Febuary 1994), pp. 467-478. ISSN 0032-0889

Webb, M. S., Uemura, M., Steponkus, P. L. (1994). A Comparison of Freezing Injury in Oat and Rye, Two Cereals at the Extremes of Freezing Tolerance. Plant Physiology, Vol.104, No.2, (February 1994), pp. 467-478, ISSN 0032-0889

Weston, E., Thorogood, K., Vinti, G., López-Juez, E. (2000). Light quantity controls leaf-cell and chloroplast development in Arabidopsis thaliana, wild type and blue-lightperception mutants. Planta, Vol.211, No.6, (November 2000) pp. 807-815, ISSN 00320935

Williams, M. E., Torabinejad, J., Cohick, E., Parker, K., Drake, E. J., Thompson, J. E., Hortter, M., DeWald, D., B. (2005). Mutations in the Arabidopsis Phosphoinositide Phosphatase Gene SAC9 Lead to Overaccumulation of $\operatorname{PtdIns}(4,5) \mathrm{P} 2$ and Constitutive Expression of the Stress-Response Pathway. Plant Physiology, Vol.138, No.2, (June 2005), pp. 686-700, ISSN 0032-0889

Witcombe, J., Hollington, P., Howarth, C., Reader, S., Steele, K. (2008). Breeding for abiotic stresses for sustainable agriculture. Philosophical Transactions of the Royal Society B: Biological Sciences, Vol.363, No.1492, (Febuary 2008), pp. 703-716, ISSN 1471-2970

Woodward, A. J., Bennett, I. J. (2005). The effect of salt stress and abscisic acid on proline production, chlorophyll content and growth of in vitro propagated shoots of Eucalyptus camaldulensis. Plant Cell, Tissue and Organ Culture, Vol.82, No.2, (January 2005), pp. 189-200, ISSN 0167-6857

Wu, G.-Q., Xi, J.-J., Wang, Q., Bao, A.-K., Ma, Q., Zhang, J.-L., Wang, S-M. (2011). The ZxNHX gene encoding tonoplast $\mathrm{Na}+\mathrm{H}+$ antiporter from the xerophyte Zygophyllum xanthoxylum plays important roles in response to salt and drought. Journal of Plant Physiology, Vol.168, No.8, (May 2011), pp. 758-767, ISSN 0032-0889

Wu, Y.-Y.,Chen, Q.-J., Chen, M., Chen, J., and Wang, X.-C. (2005). Salt-tolerant transgenic perennial ryegrass (Lolium perenne L.) obtained by Agrobacterium tumefaciensmediated transformation of the vacuolar $\mathrm{Na}+\mathrm{H}+$ antiporter gene. Plant Science, Vol.169, No.1, (July 2005), pp. 65-73, ISSN 0306-4484

Xie, C., G., Lin, H., Deng, H., W., Guo, Y. (2009). Roles of SCaBP8 in salt stress response. Plant Signal Behavior, Vol.4, No.10, (October 2009), pp. 956-958, ISSN1559-2316

Xiong, L. and Yang, Y. (2003). Disease Resistance and Abiotic Stress Tolerance in Rice Are Inversely Modulated by an Abscisic Acid Inducible Mitogen-Activated Protein Kinase. The Plant Cell, Vol.15, No.3, (March 2003), pp.45-759, ISSN 1040-4651

Xu, K., Hong, P., Luo, L., Xia, T. (2009). Overexpression of AtNHX1, a Vacuolar $\mathrm{Na}^{+} / \mathrm{H}^{+}$ Antiporter from Arabidopsis thalina, in Petunia hybrida Enhances Salt and Drought 
Tolerance. Journal of Plant Biology, Vol.52, No.5, (August 2009), pp. 453-461, ISSN 1226-9239

Xu, Y., Gianfagna, T., Huang, B. (2010). Proteomic changes associated with expression of a gene (ipt) controlling cytokinin synthesis for improving heat tolerance in a perennial grass species. Journal of Experimental Botany,Vol.61, No.12, (June 2010), ISSN 1460-2431

$\mathrm{Xu}, \mathrm{Z}$. and Zhou, G. (2006). Combined effects of water stress and high temperature on photosynthesis, nitrogen metabolism and lipid peroxidation of a perennial grass Leymus chinensis. Planta, Vol.224, No.5, (October 2006), pp. 1080-1090, ISSN 00320935

Xue, Z.-Y., Zhi, D.-Y., Xue, G.-P., Zhang, H., Zhao, Y.-X., Xia, G.-M. (2004). Enhanced salt tolerance of transgenic wheat (Tritivum aestivum L.) expressing a vacuolar $\mathrm{Na}+/ \mathrm{H}+$ antiporter gene with improved grain yields in saline soils in the field and a reduced level of leaf Na+. Plant Science, Vol.167, No.4, (October 2004), pp. 849 859, ISSN 0306-4484

Yaeno, T., Matsuda, O., Iba, K. (2004). Role of chloroplast trienoic fatty acids in plant disease defense responses. The Plant Journal, Vol.40, No.6, (September 2004), pp. 931-941, ISSN 0960-7412

Yamada, K., Fukao, Y., Hayashi, M., Fukazawa, M., Suzuki, I., Nishimura, M. (2007). Cytosolic HSP90 Regulates the Heat Shock Response That Is Responsible for Heat Acclimation in Arabidopsis thaliana. Journal of Biological Chemistry, Vol.282, No.52, (December 2007), pp. 37794-37804, ISSN 0021-9258

Yang, J. and Zhang, J. (2006). Grain filling of cereals under soil drying. New Phytologist, Vol.169, No.2, (January 2006), pp. 223-236, ISSN 0028-646X

Yang, X., Wen, X., Gong, H., Lu, Q., Yang, Z., Tang, Y., et al. (2007). Genetic engineering of the biosynthesis of glycinebetaine enhances thermotolerance of photosystem II in tobacco plants. Planta, Vol.225, No.3 (September 2007), pp. 719-733, ISSN 0032-0935

Yao, J., Roy-Chowdhury, S., Allison, L. A. (2003). AtSig5 Is an Essential Nucleus-Encoded Arabidopsis s-Like Factor. Plant Physiology, Vol.132, No.2, (June2003), pp. 739-747, ISSN 0032-0889

Yao, Y., Ni, Z., Peng, H., Sun, F., Xin, M., Sunkar, R., et al. (2010). Non-coding small RNAs responsive to abiotic stress in wheat (Triticum aestivum). Functional E; Integrative Genomics, Vol.10, No.2, (May 2010), pp. 187-190, ISSN 1438-7948

Yeo, A. (1998). Predicting the interaction between the effects of salinity and climate change on crop plants. Scientia Horticulturae, Vol.78, No.1-4, (November 1998), pp. 159-174, ISSN 0304-4238

Yokotani, N., Ichikawa, T., Kondou, Y., Matsui, M., Hirochika, H., Iwabuchi, M., et al. (2008). Expression of rice heat stress transcription factor OsHsfA2e enhances tolerance to environmental stresses in transgenic Arabidopsis. Planta, Vol.227, No.5, (April 2008), pp. 957-967, ISSN 0032-0935

Yordanov, I., Velikova, V., Tsonev, T. (2000). Plant responses to drought and stress tolerance. Photosynthetica. Vol.30, No.2, (July 2000), pp.187-206, ISSN 03003604

Yoshida, T., Sakuma, Y., Todaka, D., Maruyama, K., Qin, F., Mizoi, J., et al. (2008). Functional analysis of an Arabidopsis heat-shock transcription factor HsfA3 in the transcriptional cascade downstream of the DREB2A stress-regulatory system. 
Biochemical and Biophysical Research Communications, Vol.368, No.3, (April 2008), pp.515-521., ISSN 1090-2104

Yoshimura, K., Masuda, A., Kuwano, M., Yokota, A., Akashi, K. (2008). Programmed Proteome Response for Drought Avoidance/Tolerance in the Root of a C3 Xerophyte (Wild Watermelon) Under Water Deficits. Plant and Cell Physiology, Vol. 49. No.2, (January 2008), pp. 226-241, ISSN 0032-0781

Zelisko, A., García-Lorenzo, M., Jackowski, G., Jansson, S., Funk, C. (2005). AtFtsH6 is involved in the degradation of the light-harvesting complex II during high-light acclimation and senescence. Proceedings of the National Academy of Sciences of the United States of America, Vol.102, No.38, (September 2005), pp. 13699-13704, ISSN 0027-8424

Zhang, G.-H., Su, Q., An, L.-J., Wu, S. (2008). Characterization and expression of a vacuolar $\mathrm{Na}+/ \mathrm{H}+$ antiporter gene from the monocot halophyte Aeluropus littoralis. Plant Physiology and Biochemistry, Vol.46, No.2, (February 2008), pp. 117-126, ISSN 09819428

Zhang, H. \& Blumwald, E. (2001). Transgenic salt-tolerant tomato plants accumulate salt in foliage but not in fruit. Nature Biotechnology, Vol.19, No.8, (August 2001), pp. 756758, ISSN 1087-0156

Zhang, H., Irving, L. J., McGill, C., Matthew, C., Zhou, D., Kemp, P. (2010). The effects of salinity and osmotic stress on barley germination rate: sodium as an osmotic regulator. Annals of Botany,Vol.106, No.6, (December 2010), pp. 1027-1035, ISSN 03057364

Zhang, J., Jia, W., Yang, J., Ismail, A. M. (2006). Role of ABA in integrating plant responses to drought and salt stresses. Field Crops Research,Vol.97, No.1, (May 2006), pp. 111119, ISSN 0378-4290

Zhang, J.-L., Flowers, T., Wang, S.-M. (2010). Mechanisms of sodium uptake by roots of higher plants. Plant and Soil. Vol.326, No.1-2, (July 2010), pp. 45-60, ISSN 1573-5036

Zhang, Z. and Huang, R. (2010). Enhanced tolerance to freezing in tobacco and tomato overexpressing transcription factor TERF2/LeERF is modulated by ethylene biosynthesis. Plant Molecular Biology, Vol.73, No.3, (June 2010), pp. 241-249, ISSN 0167-4412

Zhao, J., Ren, W., Zhi, D., Wang, L., Xia, G. (2007). Arabidopsis DREB1A/CBF3 bestowed transgenic tall fescue increased tolerance to drought stress. Plant Cell Reports, Vol.26, No.9, (September 2010), pp. 1521-1528, ISSN 0721-7714

Zheng, X., Chen, B., Lu, G., Han, B. (2009). Overexpression of a NAC transcription factor enhances rice drought and salt tolerance. Biochemical and Biophysical Research Communications, Vol.379, No.4, (Febuary 2009), pp. 985-989, ISSN 0006-291X

Zhou, S., Wei, S., Boone, B., Levy, S. (2007). Microarray analysis of genes affected by salt stress in tomato. African Journal of Environmental Science and Technology, Vol.1, No.2, (September 2007), pp.014-026, ISSN 1996-0786

Zhu, J.-K. (2002). Salt and Drought Stress Signal Transduction In Plants. Annual Review of Plant Biology, Vol.53, No.1, (June 2002), pp. 247-273, ISSN 1 543-5008 


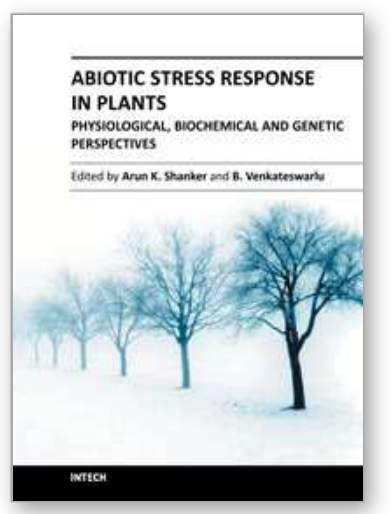

\author{
Abiotic Stress Response in Plants - Physiological, Biochemical \\ and Genetic Perspectives \\ Edited by Prof. Arun Shanker
}

ISBN 978-953-307-672-0

Hard cover, 346 pages

Publisher InTech

Published online 29, August, 2011

Published in print edition August, 2011

Plants, unlike animals, are sessile. This demands that adverse changes in their environment are quickly recognized, distinguished and responded to with suitable reactions. Drought, heat, cold and salinity are among the major abiotic stresses that adversely affect plant growth and productivity. In general, abiotic stress often causes a series of morphological, physiological, biochemical and molecular changes that unfavorably affect plant growth, development and productivity. Drought, salinity, extreme temperatures (cold and heat) and oxidative stress are often interrelated; these conditions singularly or in combination induce cellular damage. To cope with abiotic stresses, of paramount significance is to understand plant responses to abiotic stresses that disturb the homeostatic equilibrium at cellular and molecular level in order to identify a common mechanism for multiple stress tolerance. This multi authored edited compilation attempts to put forth an all-inclusive biochemical and molecular picture in a systems approach wherein mechanism and adaptation aspects of abiotic stress are dealt with. The chief objective of the book hence is to deliver state of the art information for comprehending the effects of abiotic stress in plants at the cellular level.

\title{
How to reference
}

In order to correctly reference this scholarly work, feel free to copy and paste the following:

Erik R. Rowley and Todd C. Mockler (2011). Plant Abiotic Stress: Insights from the Genomics Era, Abiotic Stress Response in Plants - Physiological, Biochemical and Genetic Perspectives, Prof. Arun Shanker (Ed.), ISBN: 978-953-307-672-0, InTech, Available from: http://www.intechopen.com/books/abiotic-stress-responsein-plants-physiological-biochemical-and-genetic-perspectives/plant-abiotic-stress-insights-from-the-genomicsera1

\section{INTECH}

open science | open minds

\section{InTech Europe}

University Campus STeP Ri

Slavka Krautzeka 83/A

51000 Rijeka, Croatia

Phone: +385 (51) 770447

Fax: +385 (51) 686166

www.intechopen.com

\section{InTech China}

Unit 405, Office Block, Hotel Equatorial Shanghai

No.65, Yan An Road (West), Shanghai, 200040, China 中国上海市延安西路65号上海国际贵都大饭店办公楼405单元

Phone: +86-21-62489820

Fax: $+86-21-62489821$ 
(C) 2011 The Author(s). Licensee IntechOpen. This chapter is distributed under the terms of the Creative Commons Attribution-NonCommercialShareAlike-3.0 License, which permits use, distribution and reproduction for non-commercial purposes, provided the original is properly cited and derivative works building on this content are distributed under the same license. 